\title{
A Time Domain Survey of the Los Alamos Region, New Mexico
}

它

4

$\frac{\lambda}{\infty}$

(1)

$\frac{2}{5}$ 


\section{DISCLAIMER}

This report was prepared as an account of work sponsored by an agency of the United States Government. Neither the United States Government nor any agency Thereof, nor any of their employees, makes any warranty, express or implied, or assumes any legal liability or responsibility for the accuracy, completeness, or usefulness of any information, apparatus, product, or process disclosed, or represents that its use would not infringe privately owned rights. Reference herein to any specific commercial product, process, or service by trade name, trademark, manufacturer, or otherwise does not necessarily constitute or imply its endorsement, recommendation, or favoring by the United States Government or any agency thereof. The views and opinions of authors expressed herein do not necessarily state or reflect those of the United States Government or any agency thereof. 


\section{DISCLAIMER}

Portions of this document may be illegible in electronic image products. Images are produced from the best available original document. 
This work was supported by the US Department of Energy, Division of Geothermal Energy.

This report was prepured at an account of work sponsored by the United States Government. Neither the United Stutes not the United States Department of Energy, nor any of their employees. nor any of their contractors, subeontructors, or their employees, makes any warranty, express or implied, or assumes any lezal liability or responsibility for the accuracy. completeness. or usefulness of any information, apparatus. product, or process disclosed, or represents thut its use would not infringe privately owned rights. 
LA-7657-MS

Informal Report

UC-66a

Issued: January 1979

\title{
A Time Domain Survey of the Los Alamos Region, New Mexico
}

\author{
Williston, McNeil and Associates*
}

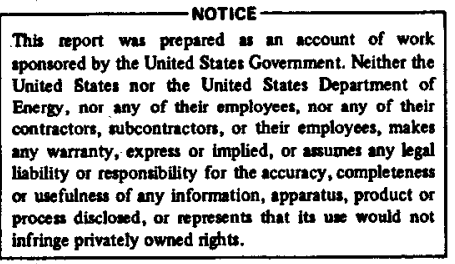

*9250 West 5th Avenue, Lakewood, CO 80226.

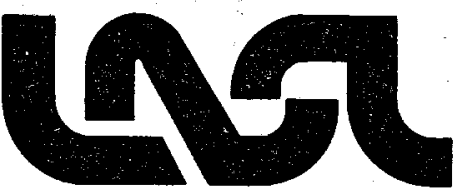


A TIME DOMAIN SURVEY OF THE LOS ALAMOS REGION, NEW MEXICO

by

Williston, McNeil and Associates

\begin{abstract}
A time domain electromagnetic sounding survey of the region surrounding the city of Los Alamos, New Mexico was carried out. The results show that a linear trough, trending northeast-southwest runs beneath the city. The southern boundary is somewhat to the south of the city, the northern boundary was not established. The geoelectric section consists of three layers and the total thickness of the section is in excess of $3000 \mathrm{~m}$. The resistivities of the second layer are as low as $2.5 \Omega \mathrm{m}$. If the salinities are in the region of $7000 \mathrm{ppm}$, the resistivities could indicate that water with a temperature of $150^{\circ} \mathrm{C}$ may be found at a depth of $3000 \mathrm{~m}$.
\end{abstract}

\title{
I. INTRODUCTION
}

Williston, McNeil \& Associates carried out a time domain electromagnetic (TDEM) survey in and about the city of Los Alamos, New Mexico. The purpose of the survey was to study the geothermal potential of the area. A single electrical dipole source was established to the south of the area of interest and 50 receiver sites were occupied (PIate 1). The recording locations were specified by some of the staff of the Los Alamos Scientific Laboratory (LASL). The results of the survey are presented on a base map supplied by LASL at a scale of 1:24 000 . Plates 1,2 , and 3 are in a pocket on the inside back cover of this report.

\section{METHOD}

The TDEM sounding technique measures the time rate of decay of the vertical component of the magnetic field generated by a square wave of current injected into the earth by an electric dipole source (Fig. 1).1 A single-source dipole $0.6 \mathrm{~km}$ long of \#2 A.W.G. wire was used; power was supplied by a $200-\mathrm{kW}$ diesel generator and the resulting current square wave attained up to $350 \mathrm{~A}$ peak to peak. The transmitted signal was measured by a single-axis cryogenic magnetometer employing a Josephson junction in a liquid-helium-filled dewar. This instrument has an effective area of $23.4 \mathrm{~km}^{2}$; attenuation and filtering are selectable. Cryogenic 


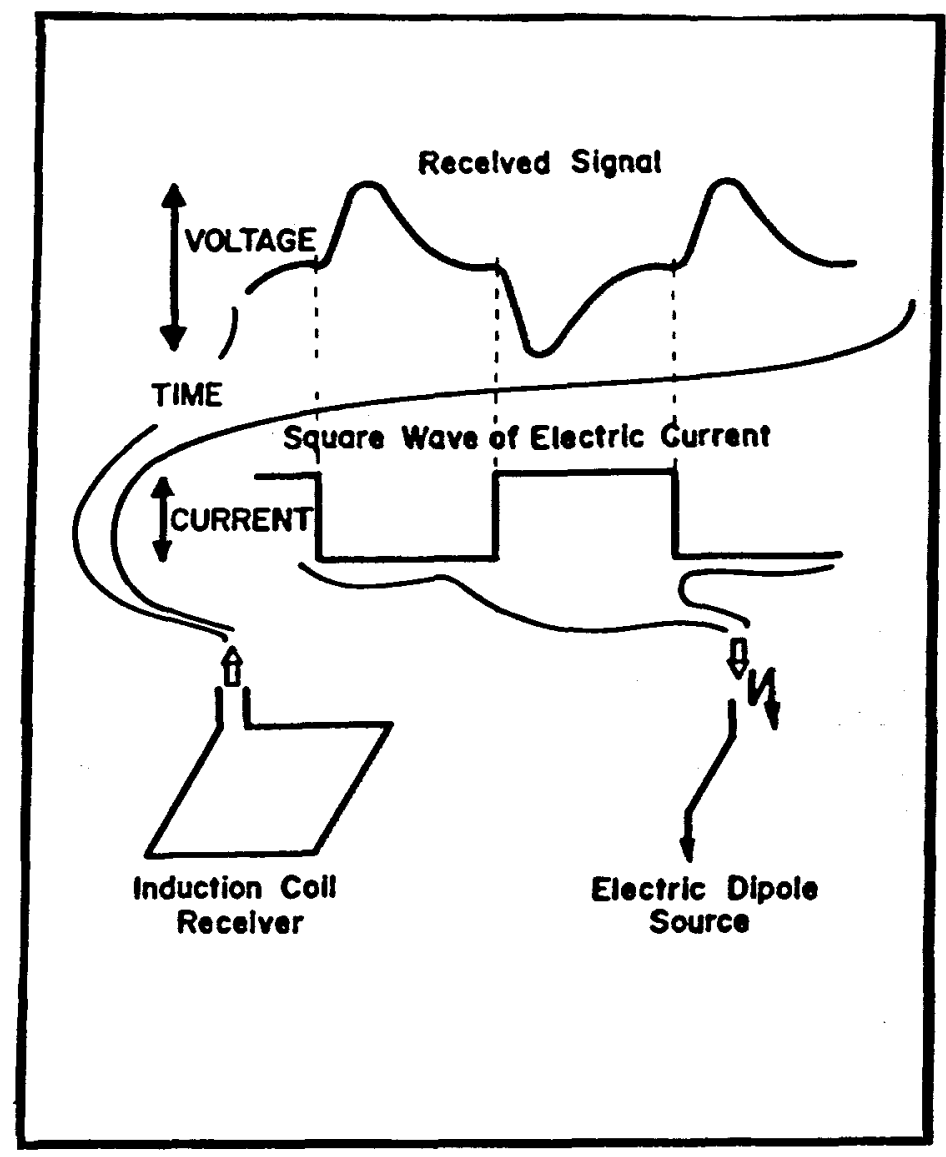

Fig. 1.

Time-domain electromagnetic sounding: equipment schematic.

magnetometers have significant advantages over the induction loops used during the development of the TDEM method. The two major advantages are much greater ease of setting up and greatly increased effective areas.

While penetration of an electromagnetic wave is basically controlled by skin depth, the offset distance is also a factor. As the distance between the source and the measuring point is increased, the lower frequencies, i.e., those with greater penetration, predominate more in the received signal. It is possible to distinguish horizontal boundaries to depths of between $1 / 3$ and $1 / 2$ of the offset distance. In Plate 1 , it can be seen that offset distances of between $3 \mathrm{~km}$ and $15 \mathrm{~km}$ were attained. The voltage measured at the receiver is

$$
v(t)=\frac{3 A L I \cos \theta}{2 R^{4}} \rho a,
$$

where

$v(t)=$ voltage at any given time after the initiation of the transient,

$A=$ effective area of the receiver in square meters,

$L=$ source length in meters

$I$ = current in source in amperes,

$\rho a=$ apparent resistivity in ohm meters, 
$\theta=$ angle between vector from source to receiver and perpendicular bisector of source, and

$R=$ distance between source center and receiver in kilometers.

Equation 1 shows that signal strength is azimuthally dependent, and it decreases from the perpendicular bisector of the source dipole to the sides.

In the fleld, the data were recorded using a digital data retrieval system based on an LSI 11 computer. Subsequent processing of the signal involves deconvolution of the signal response of the recording equipment and logarithmic filtering to remove noise. Finally, the voltage-versus-time curve is transformed into a resistivity-versus-time curve using Eq. (1). The voltage-versustime curve and resistivity-versus-time curves are shown in Appendix $B$.

The interpretation of the curves was carried out using a computer inversion program that is based on a layered-earth model. This program inverts the resistivity-versus-time curve to a series of discrete layers which are characterized by thickness and resistivity (Appendix A). These geoelectric layers may or may not coincide with actual rock units. To be completely diagnostic, the TDEM soundings must be related to well log information. In each sounding interpreted in the present survey, the lowermost layer is a resistor deeper than whose surface no further geoelectric layers can be distinguished. This lowermost layer is known as electrical basement. However, it may not coincide with basement as it is known to a geologist--meaning that granitic or metamorphic rocks are present. For example, limestones and dolomites will appear as electrical basement because of their high resistivity as will any other rock provided there is sufficient resistivity contrast of about 10 to 1 between the rock and the layer immediately above.

\section{RESULTS}

Four geoelectric parameters are presented in Appendix $A$. They are resistivity and thickness of the first geoelectric layer, and resistivity and thickness of the second geoelectric layer. Also listed in Appendix $A$ is the percentage error in the fit of the inverted model.

In Plate 1 is shown the depth to the electric basement. The principal feature of Plate 1 is a well-defined trough with an axis running northeastsouthwest. In the center the trough is $3435 \mathrm{~m}$ deep. It shallows to the northeast, but the coverage is not sufficient to say whether or not it is a closed feature. To the west, near the junction of East Jemez Road and Trinity Road, the transients all have reversed initiations (soundings 110-116). This behavior indicates that there is a strong lateral increase in resistivity to the west. The boundary between the two resistivity zones is probably a fault.

Insofar as geothermal exploration is concerned, the deeper layers are normally more interesting than the shallow. In Plate 2 the thickness of the second layer, i.e., the one immediately above electrical basement, is shown. The thickest part of layer two coincides with the deepest part of the total section as shown in Plate 2. The layer thins rapidly to the south and to the southwest. Its maximum thickness is in excess of $2000 \mathrm{~m}$. 
The resistivities of the first layer are quite variable (Appendix A) and are not presented in map form. However, the second layer resistivities show a variation that is consistent with their depth of burial within the trough. These resistivities are shown in Plate 3. The major feature is a low of less than $2.5 \Omega \mathrm{m}$ in the center part of the prospect. The resistivities increase away from this central low. To the northeast there is an increase to $3.5 \Omega \mathrm{m}$, whereas to the west the resistivities increase to greater than $7 \Omega \mathrm{m}$. The lowest resistivities are coincident with the axis of the trough.

\section{CONCLUSIONS AND RECOMMENDATIONS}

Underneath the city of Los Alamos there is a deep trough or graben that extends to the northeast away from the town. The graben is in excess of $3000 \mathrm{~m}$ deep and is made up of two geoelectric layers. The upper layer is variable in resistivity and thickness (Appendix $A$ ). The second and lower layer is over $2000 \mathrm{~m}$ thick and has resistivities that are as low as $2 \Omega \mathrm{m}$. The low-resistivity zone (less than $5 \Omega \mathrm{m}$ ) lies in the middle of the graben. These resistivities are typical of a fine-grained rock of either sedimentary or volcanic origin. However, the resistivities are too low to be those of rock containing fresh water, the interstitial fluid must be affected either by salinity or by an increase in temperature. The low resistivities indicate that the rocks must have a porosity of greater than 20 percent. For example, if the rock has a formation factor of 10 and the pore waters have a salinity of $7000 \mathrm{ppm}$, then the temperature would be $150^{\circ} \mathrm{C}$. In the volcanic terrain surrounding Los Alamos, it is quite conceivable that such temperatures could be reached toward the bottom of a 3 048-m (10 000-ft) bore hole.

Electromagnetic transients may be transformed from curves of voltage versus time to resistivity versus time using one of two asymptotic formulas. The formula used to convert the curves in this report is the "early time" or "far zone" formula in which the receiver locations must be at a distance of several source lengths from the transmitter. The soundings which lie between the source and Pajarito Road do not fulfill this criterion. In order to interpret them, they will be reprocessed using the late time asymptotic approximation and then interpreted in terms of geoelectric layers. Until these results are available, it is suggested that the results of the TDEM survey be extended using other geophysical techniques such as gravity.

\section{REFERENCE}

1. N. Harthill, "Time-Domain El ectromagnetic Sounding," IEEE Trans. GE-14, 256-260 (1976). 
APPENDIX A

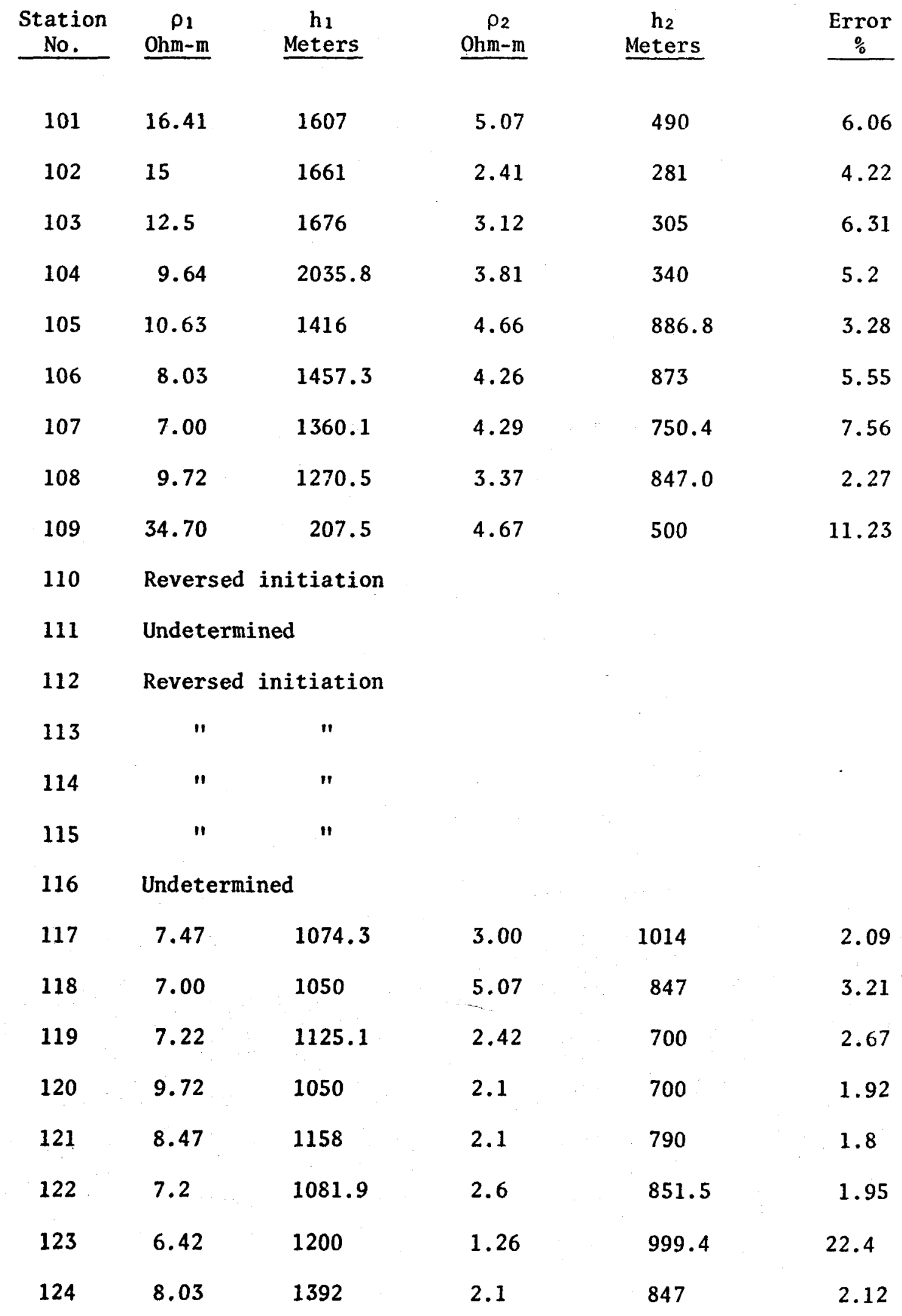




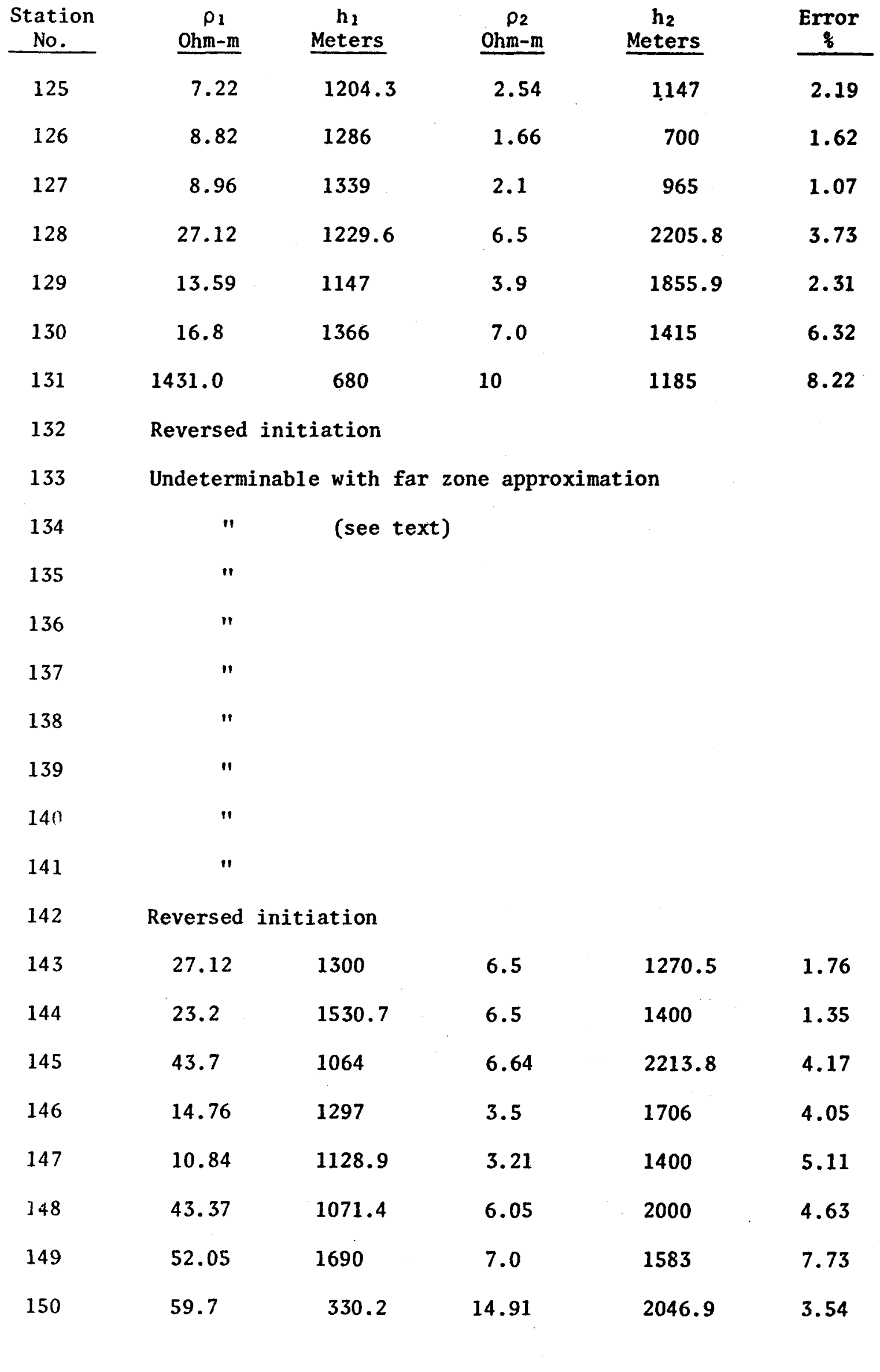


APPENDIX B

VOLTAGE-VERSUS-TIME CURVES AND RESISTIVITY-VERSUS-TIME CURVES 

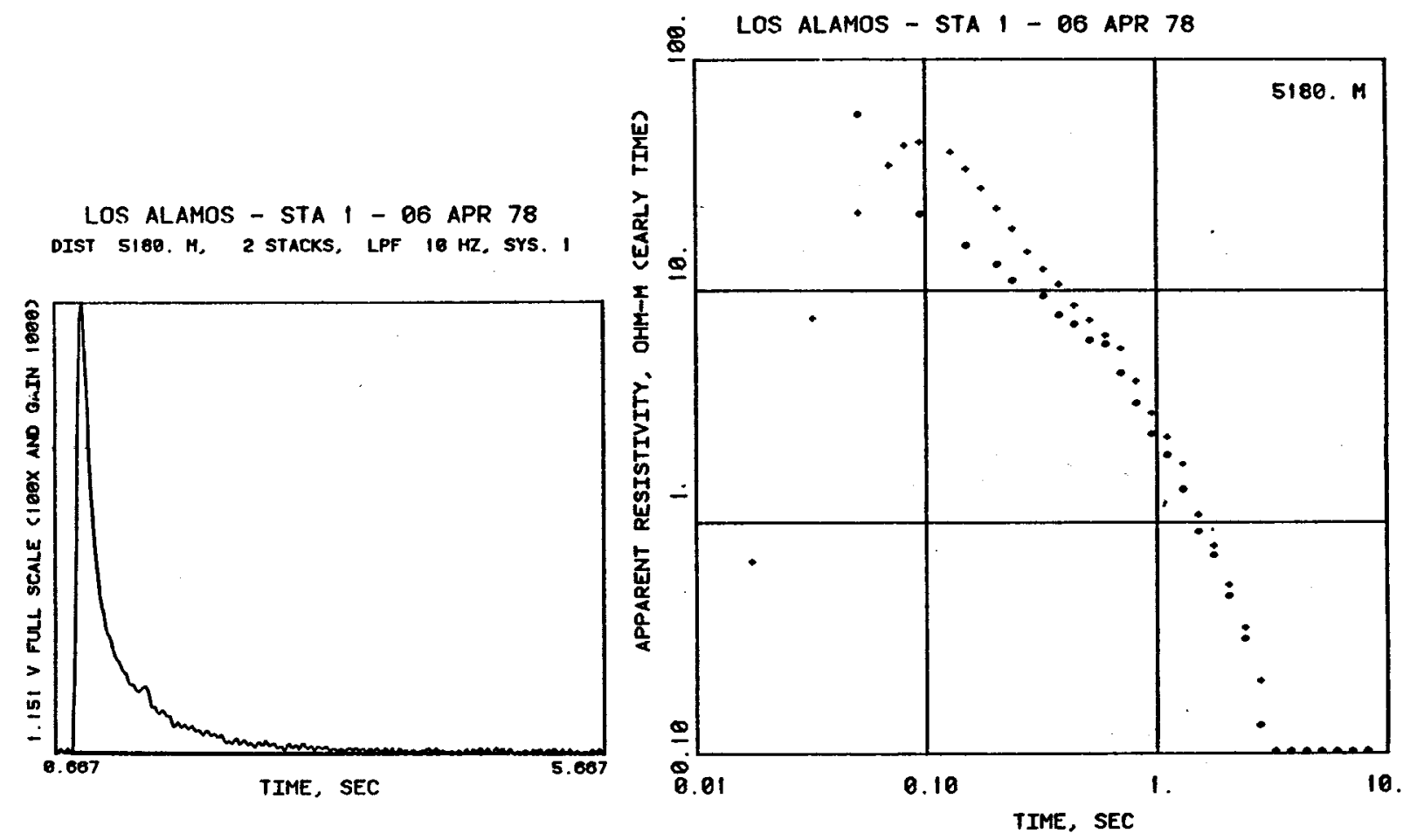

LOS ALAMOS - STA 2 - D6 APR 78 DIST 5078. M, 12 STACKS, LPF $18 \mathrm{HZ}$, SYS. I
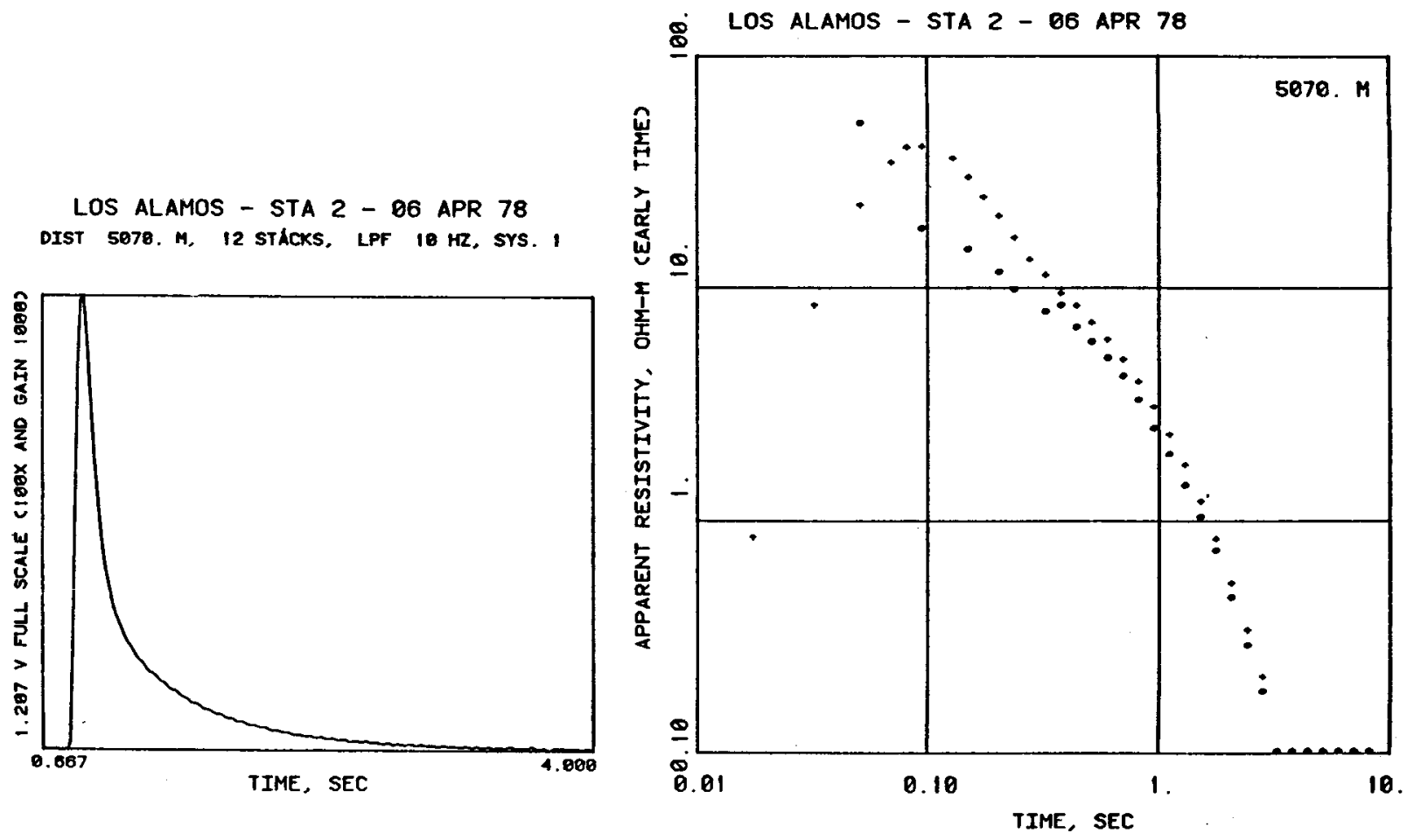
LOS ALAMOS - STA 3 - 06 APR 78 DIST 4940. M, 3 STACKS, LPF $18 \mathrm{HZ}$, SYS. I

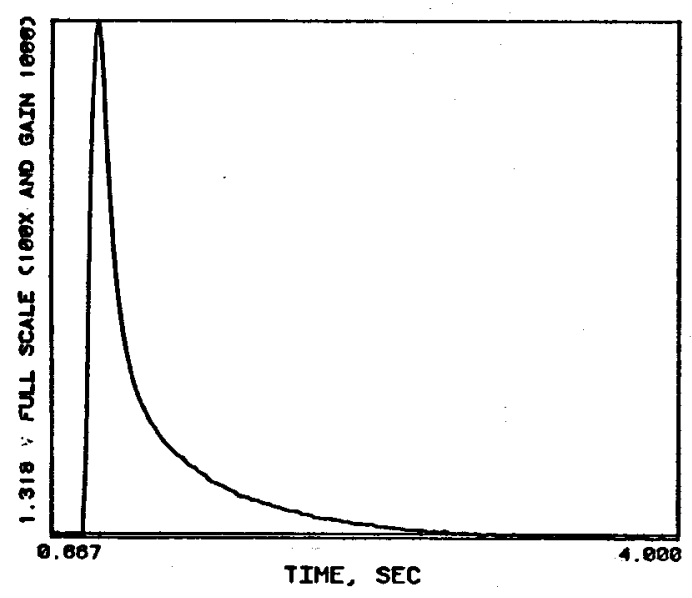

LOS ALAMOS - STA 4 - 66 APR 78 DIST $4880 . M$. STACKS. LPF $10 \mathrm{MZ}$, SYS. I

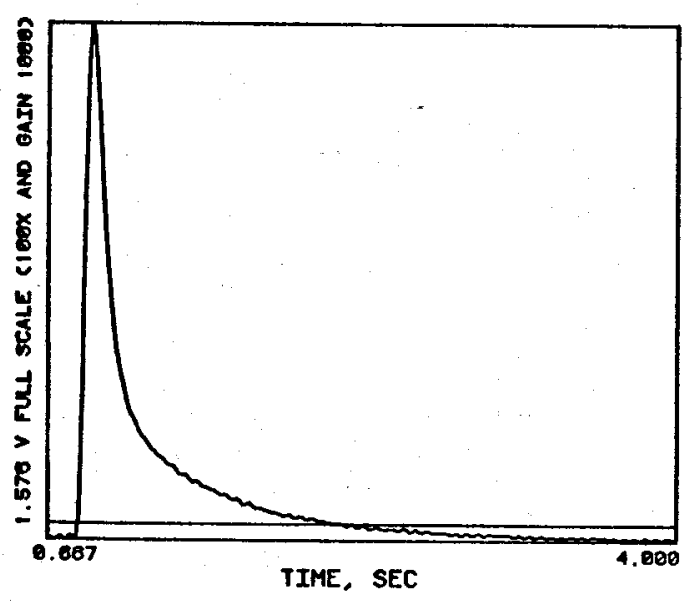

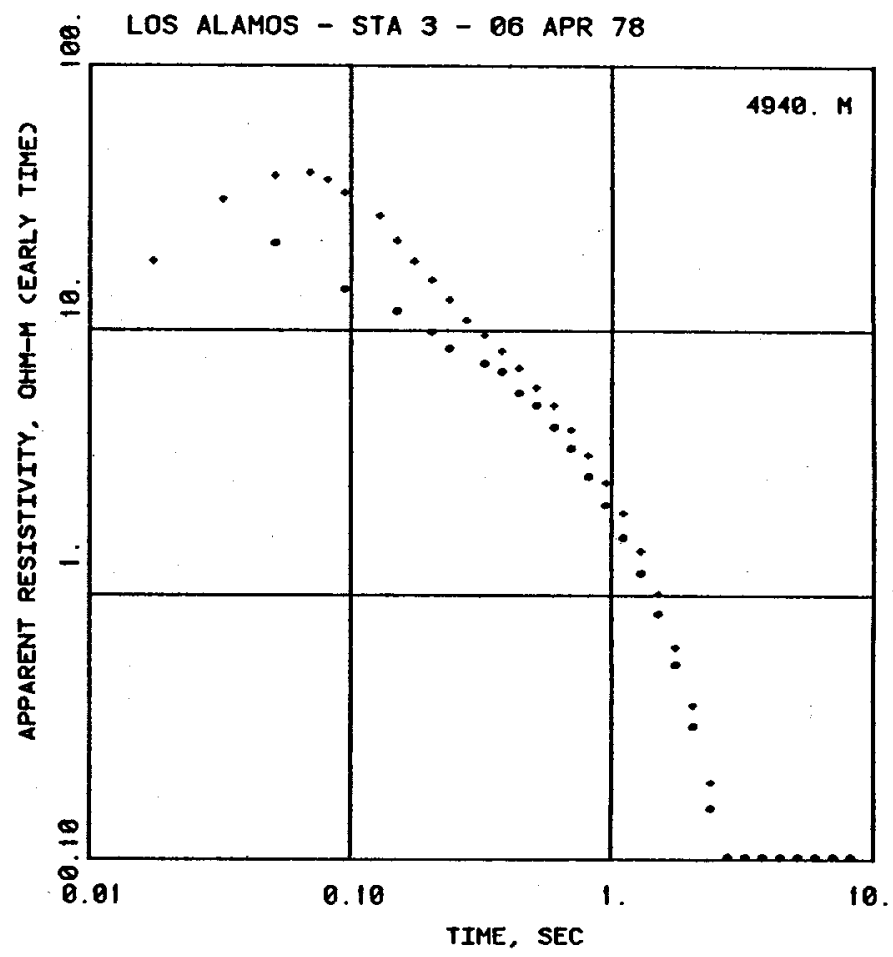

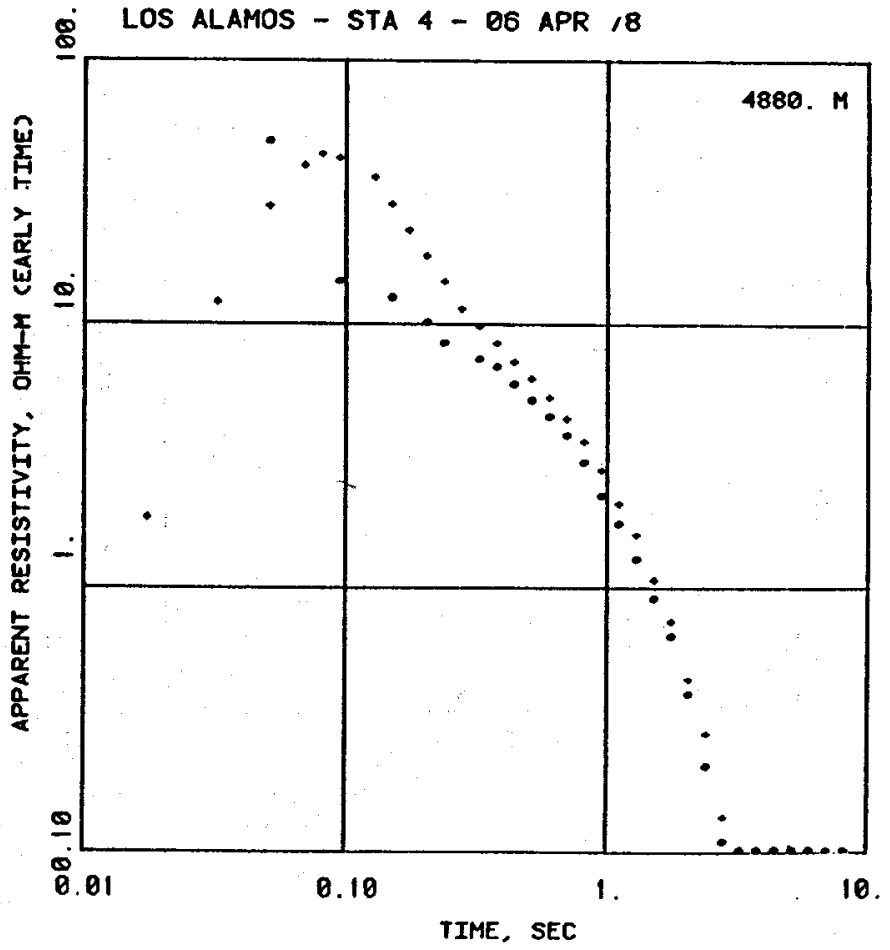


LOS ALAMOS - STA 5 - 6 APR 78

DIST 4608. M. B STACKS. LPF $18 \mathrm{kz}$, SYS. I

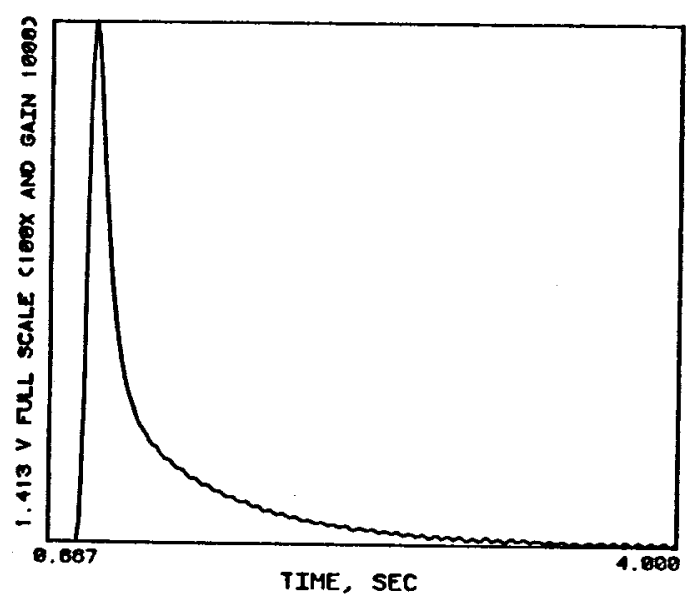

LOS ALAMOS - STA 6 - 6 APR 78 DIST 4800. $\mathrm{M}, 2$ STACKS, LPF $10 \mathrm{HZ}$, SYS. I

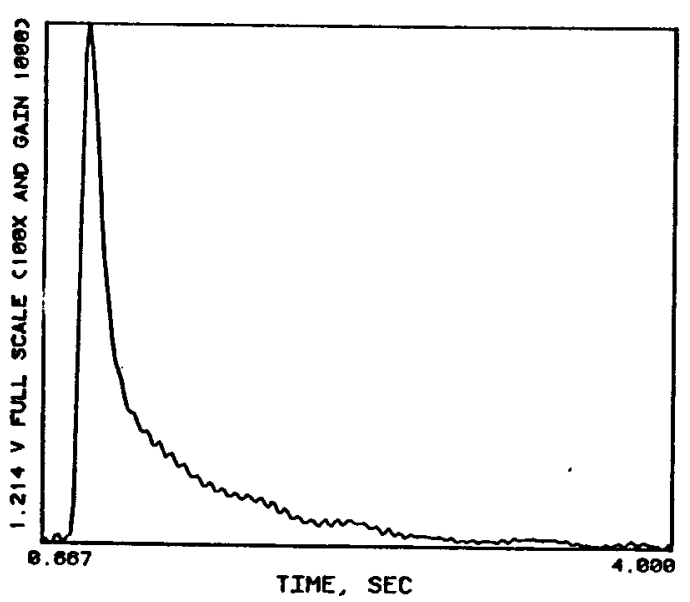

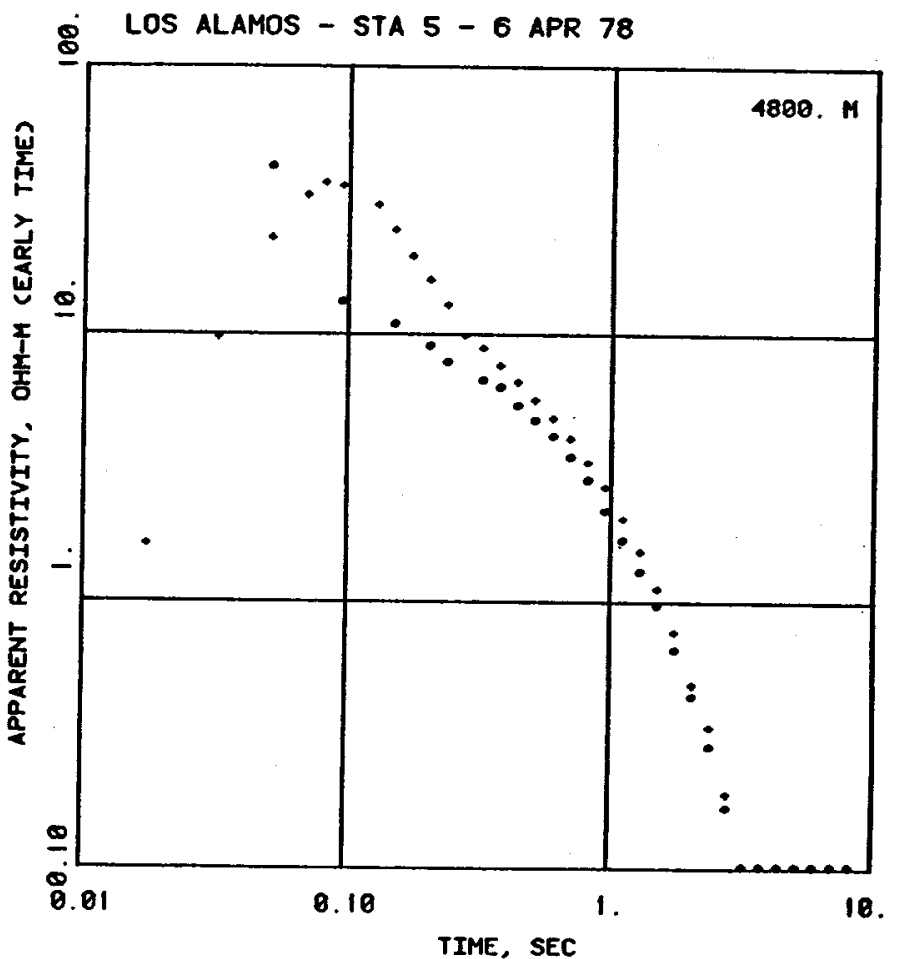

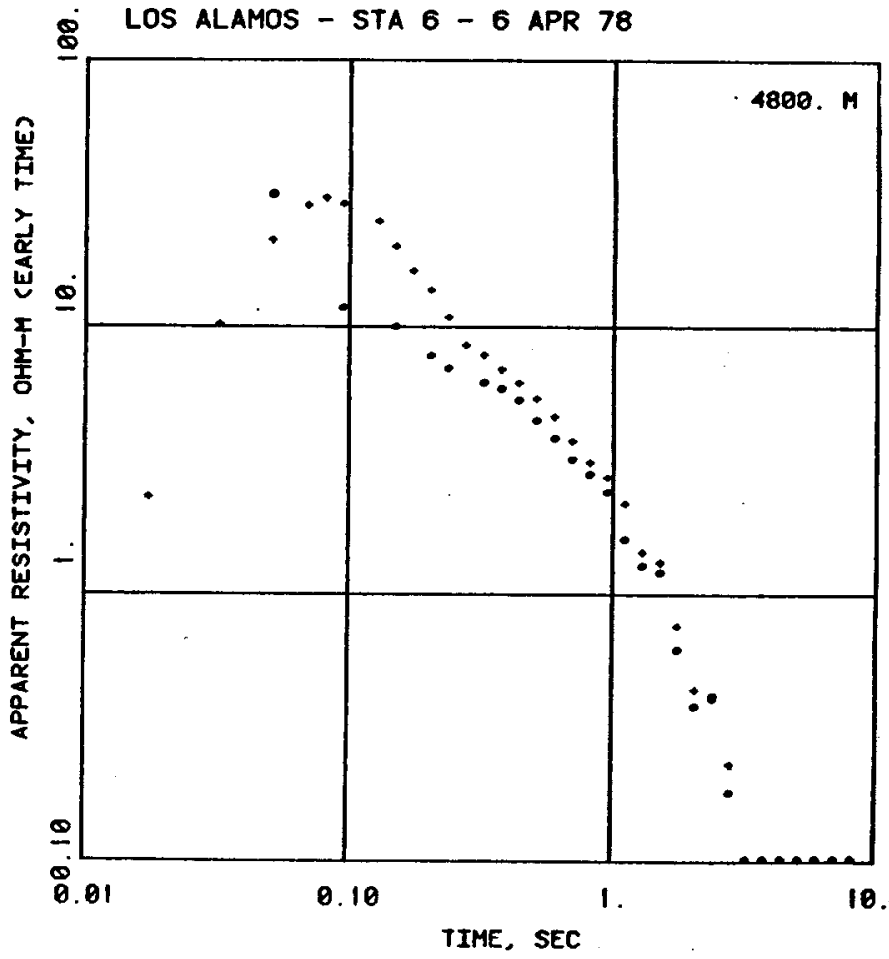


LOS ALAMOS - STA 7 - 6 APR 78

DIST 4768. H. 18 staCks, LPF I0 HZ, SYS. I

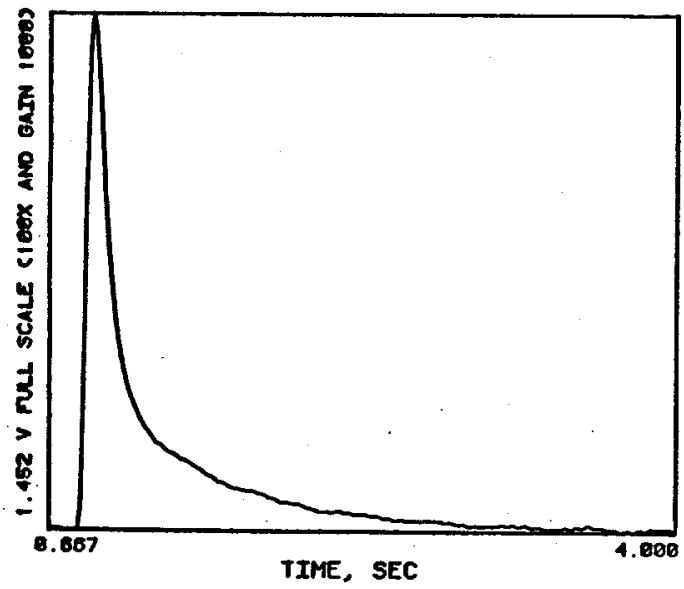

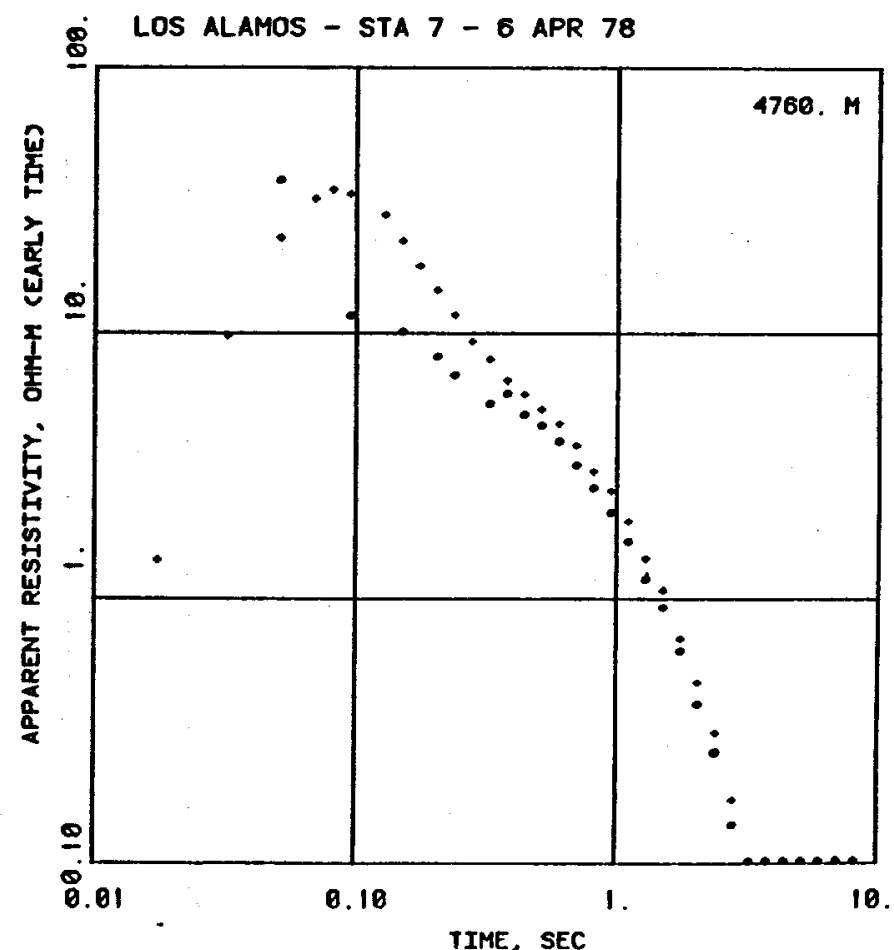

TIME, SEC
LOS ALAMOS - STA 8 - 6 APR T8 DIST 4840 . M. 11 STACKS, LPF $10 \mathrm{~Hz}$, SYS. I

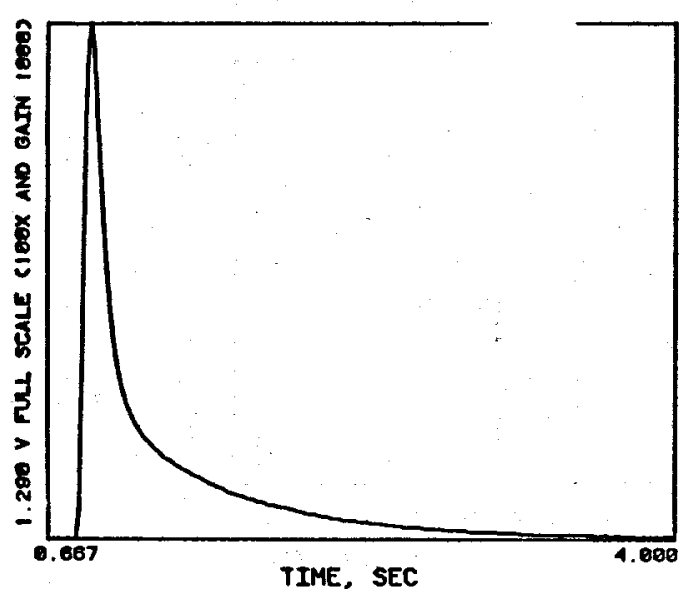

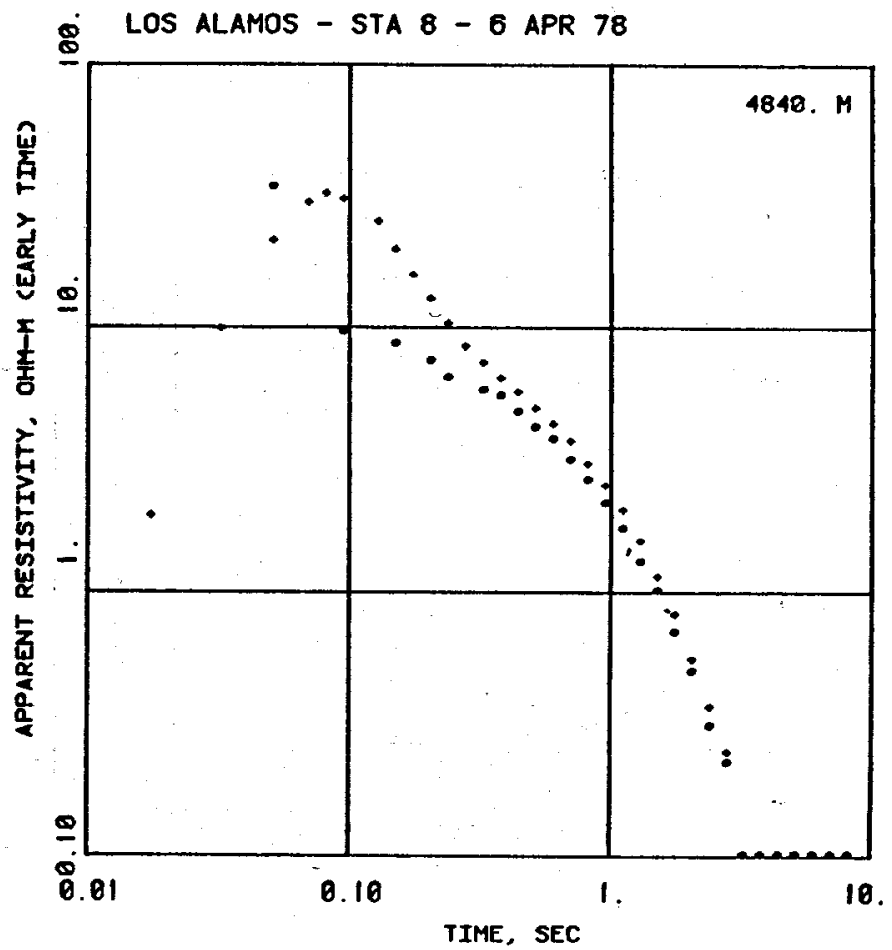


LOS ALAMOS - STA 9 - 6 APR 78 DIST 5300. M, 17 ST'ACKS, LPF $18 \mathrm{HZ}$, SYS. I

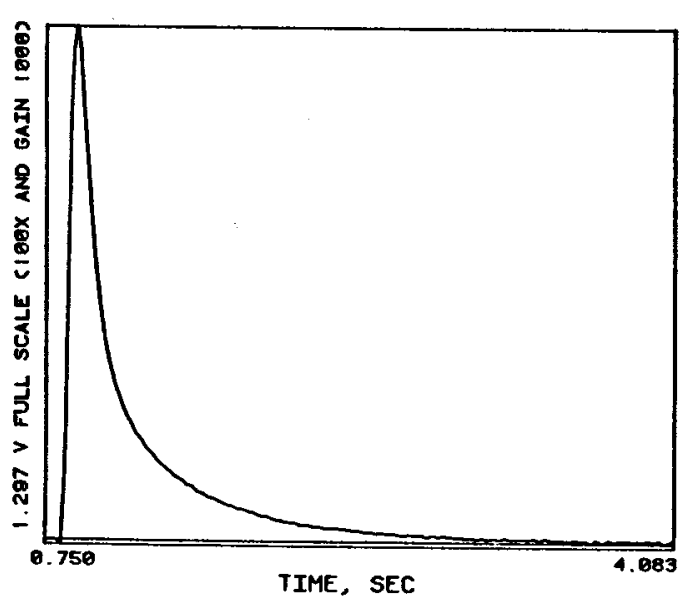

LOS ALAMOS - STAIO - 6 APR 78 DIST 5558. M, 21 STACKS. LPF $10 \mathrm{HZ}$, SYS. I

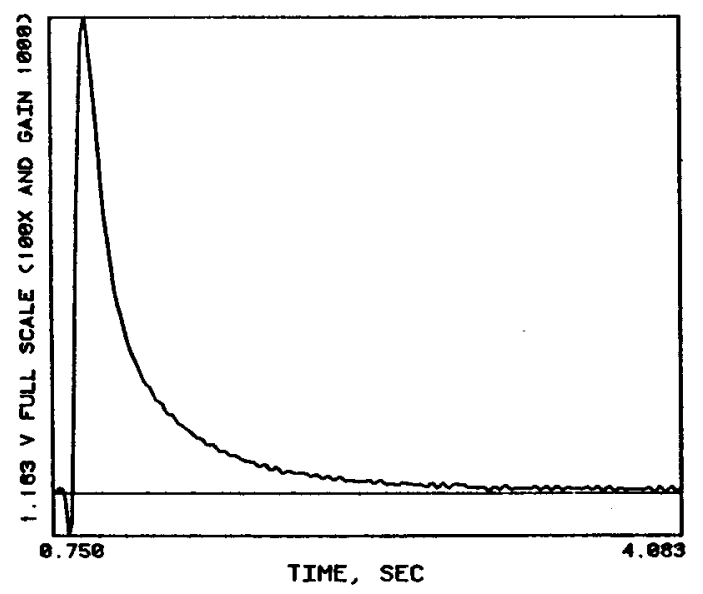

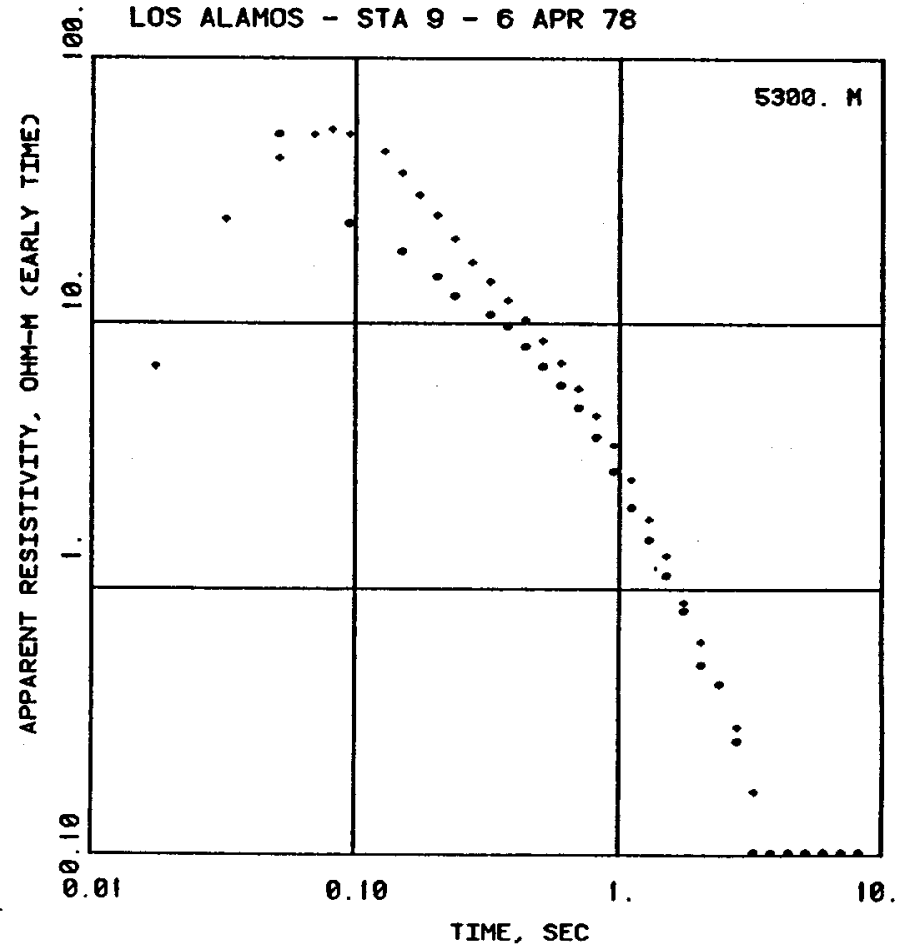

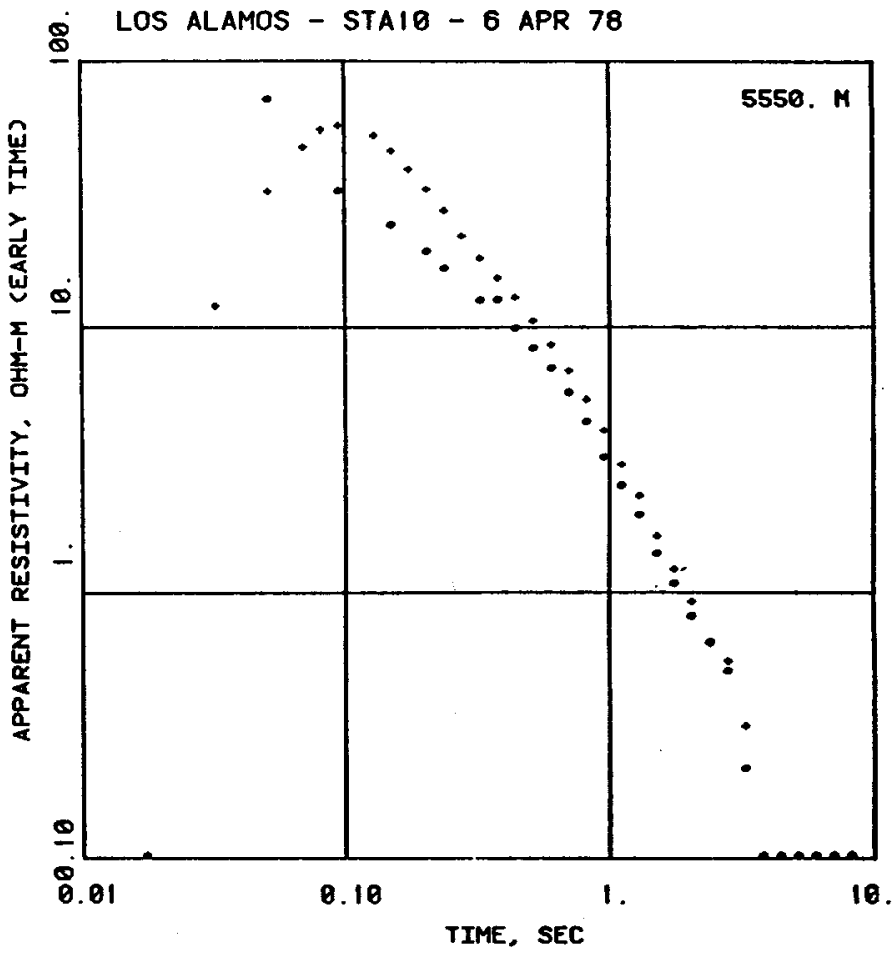


LOS ALAMOS - STA 11 - 6 APR 78 DIST 6520. $\mathrm{M}, 7$ STACKS, LPF $16 \mathrm{~Hz}$. SYS. I

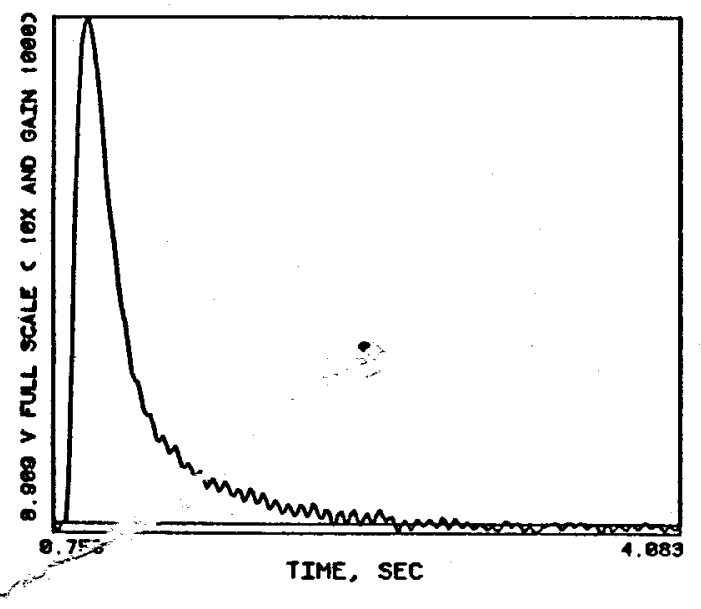

LOS ALAMOS - STA 12 - 06 APR 78 DIST 7240. H, 2 STACKS, LPF $10 \mathrm{KL}$, SYS. I

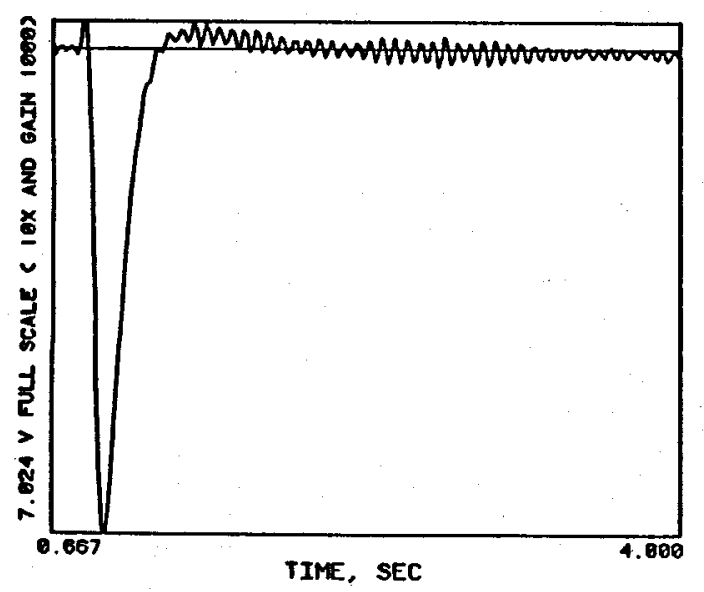

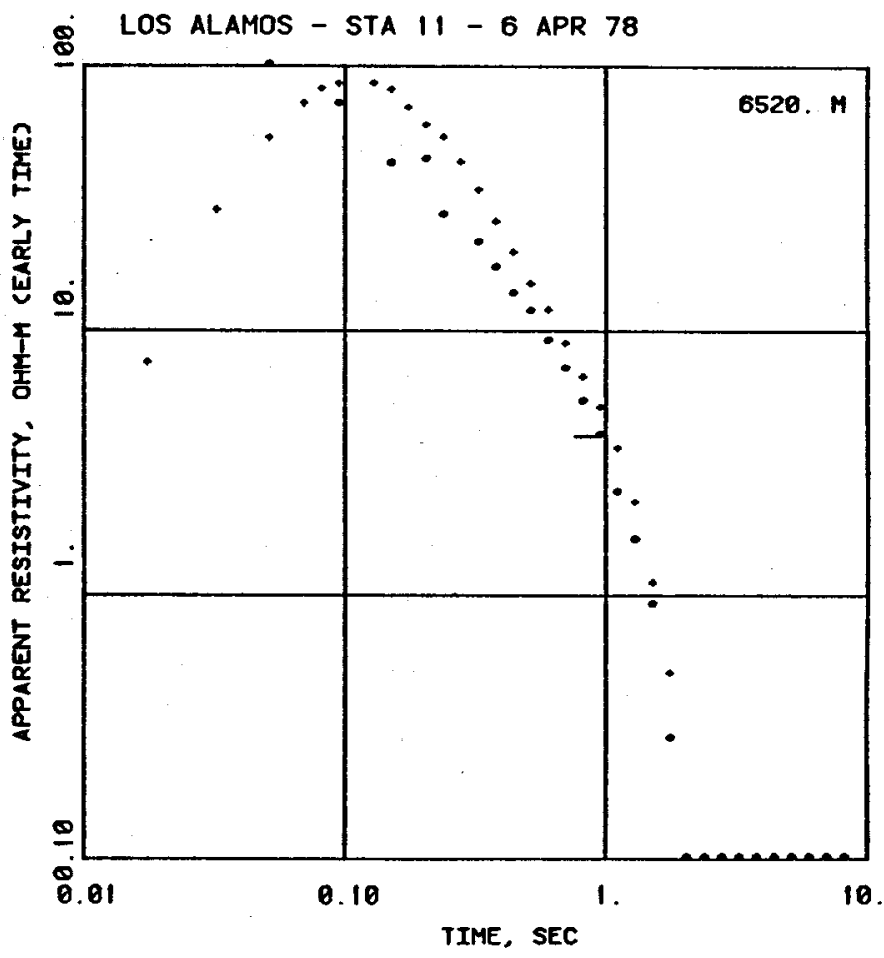

LOS ALAMOS - STA 13 - 86 APR 78 DIST 7320. H, $O$ STACKS, LPF $10 \mathrm{HZ}$, SYS. I

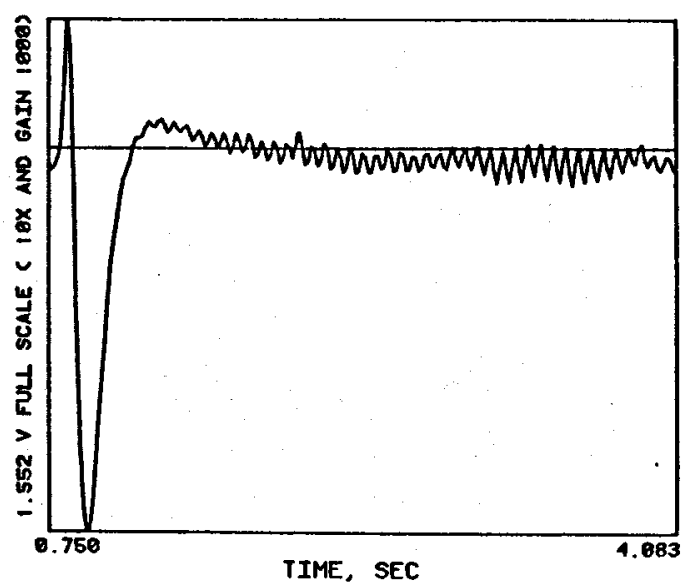



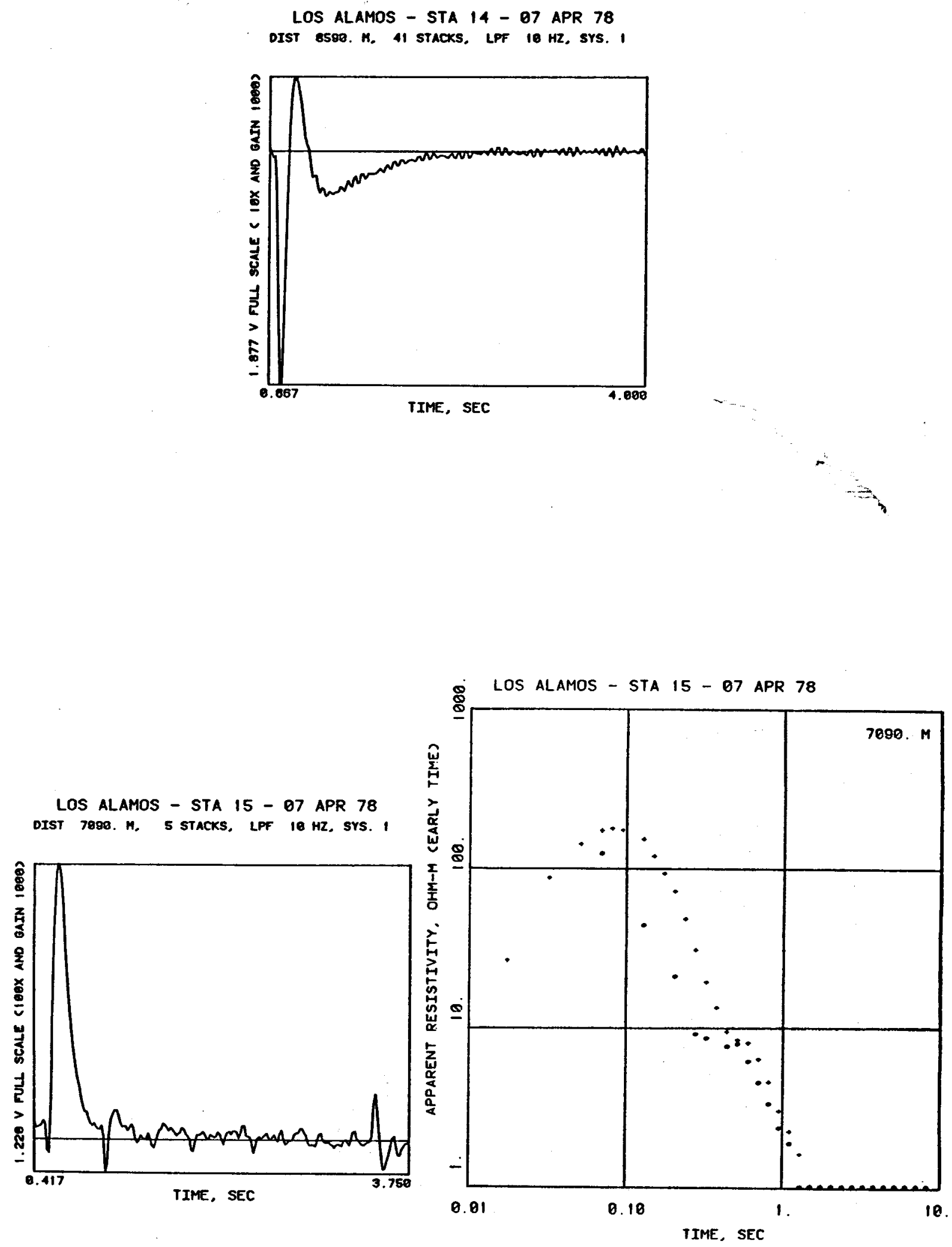
LOS ALAMOS - STA 16 - 67 APR 78

DIST Eieo. M, 5 stACKS. LPF $10 \mathrm{kz}$, sYS. I

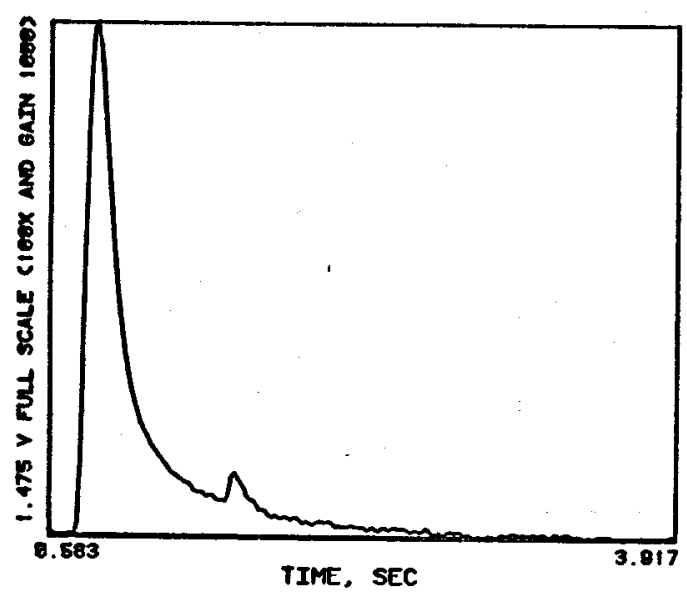

LOS ALAMOS - STA 17 - 07. APR 78 DIST 4188. $\mathrm{H}, 18$ stACKS, LPF IO HZ, SYS. I

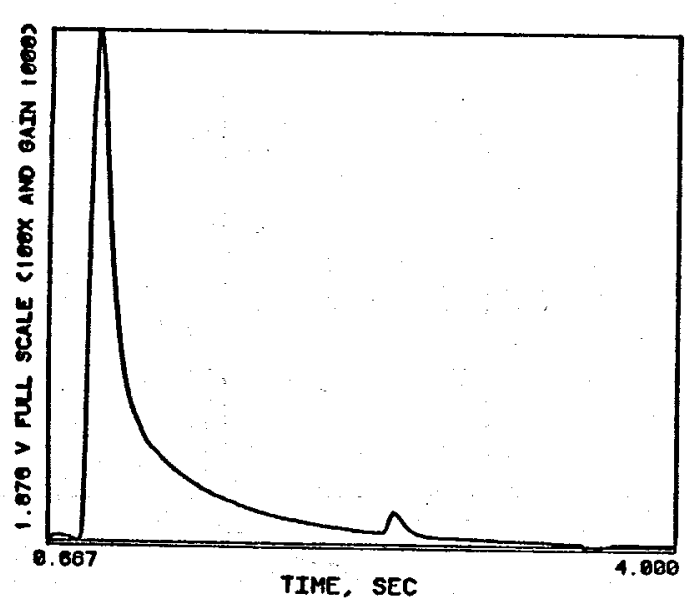

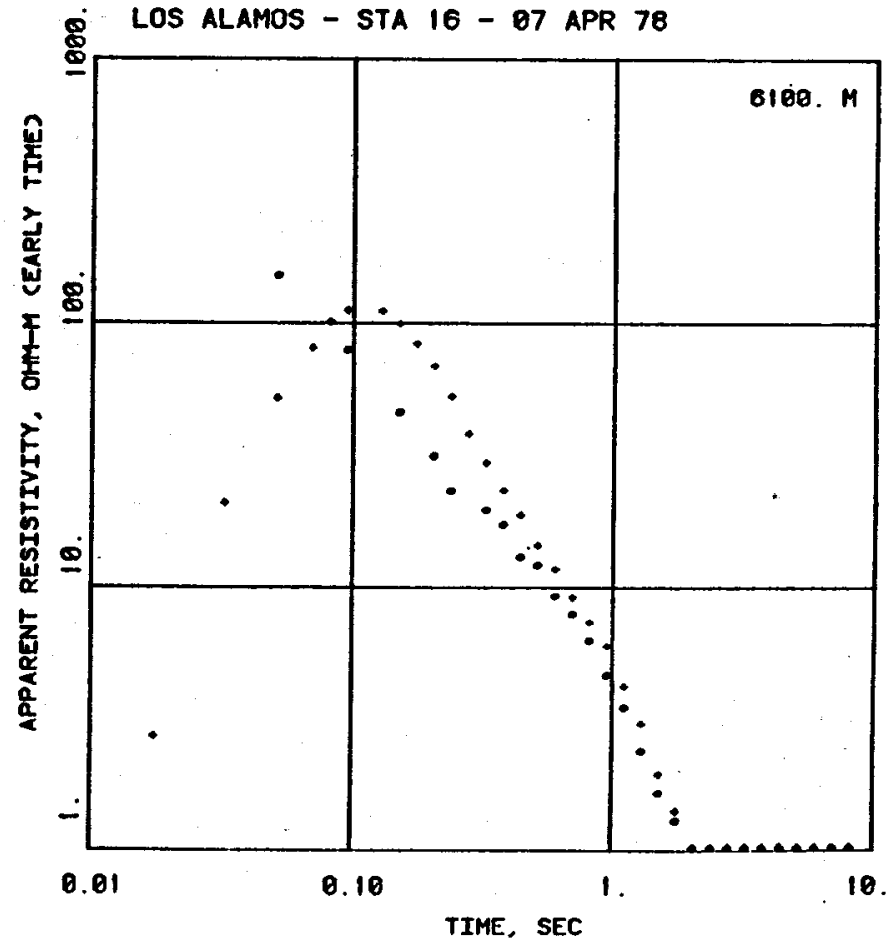

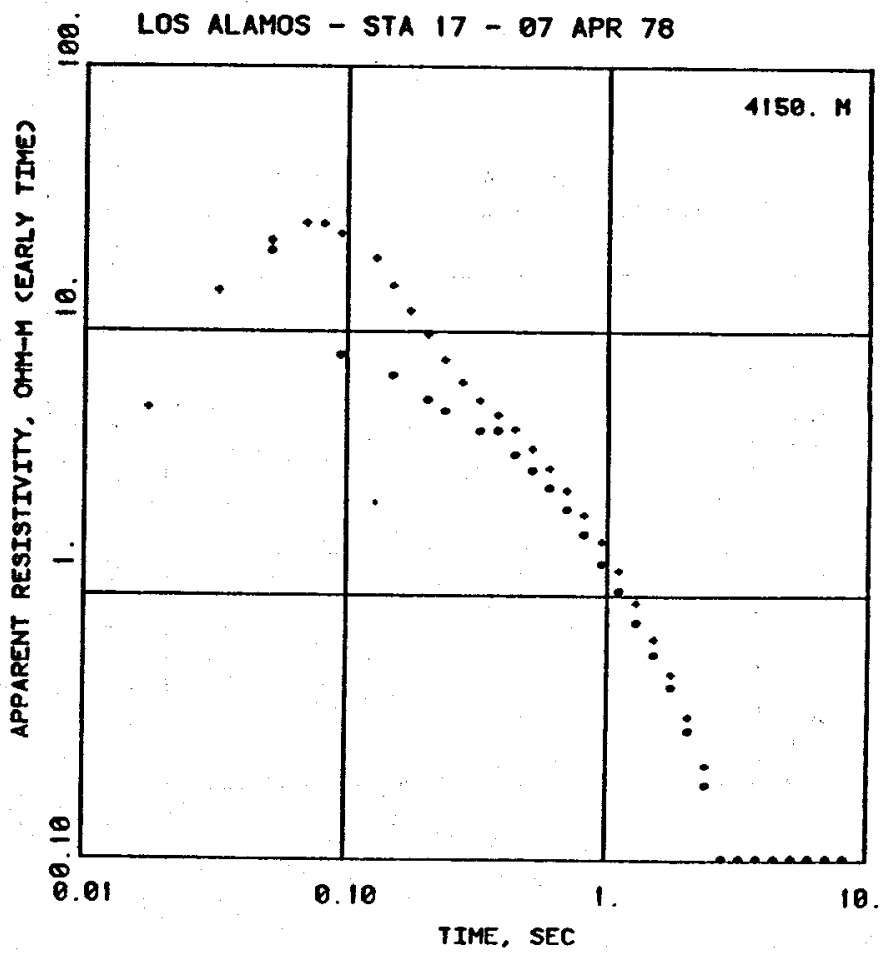


LOS ALAMOS - STA 18 - 07 APR 78 DIST $4180 . M, 34$ STACKS, LPF $10 \mathrm{HZ}$, SYS. I

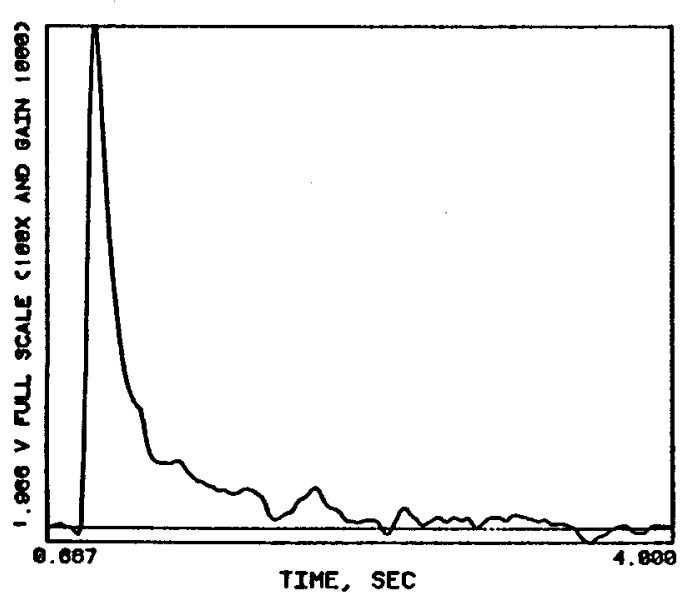

LOS ALAMOS - STA 19 - 67 APR 78 DIST 4230. $M, 8$ stACKS, LPF $10 \mathrm{HZ}$, SYS. 1

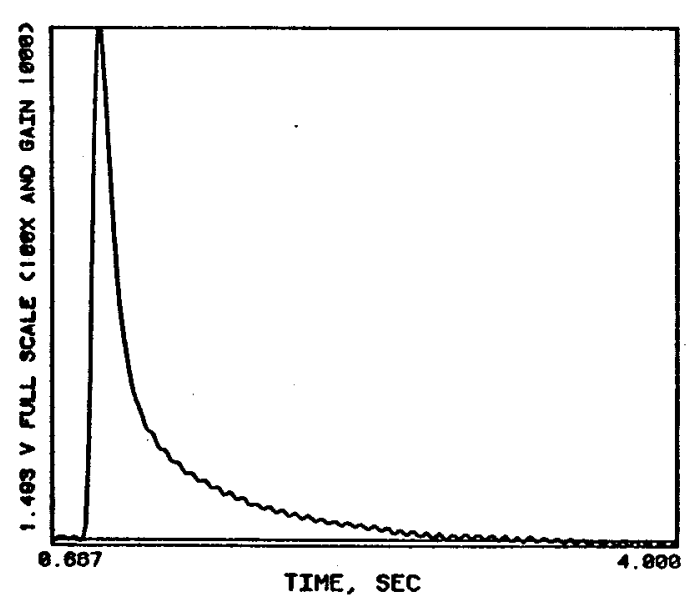

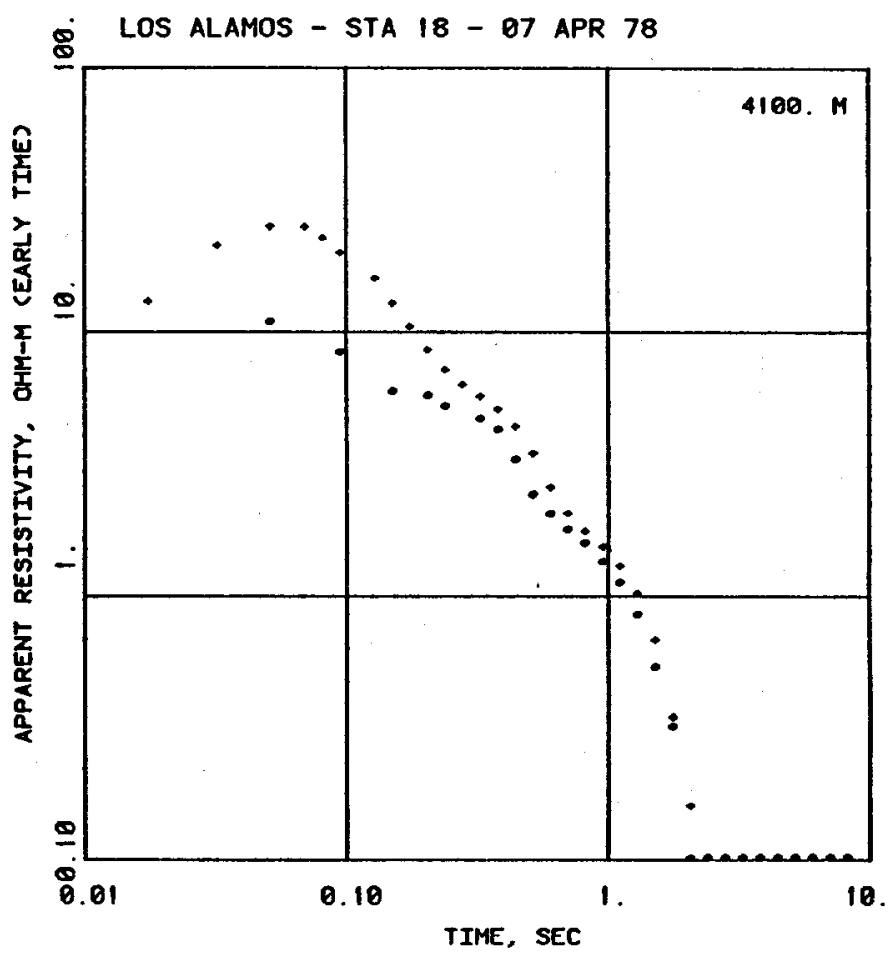

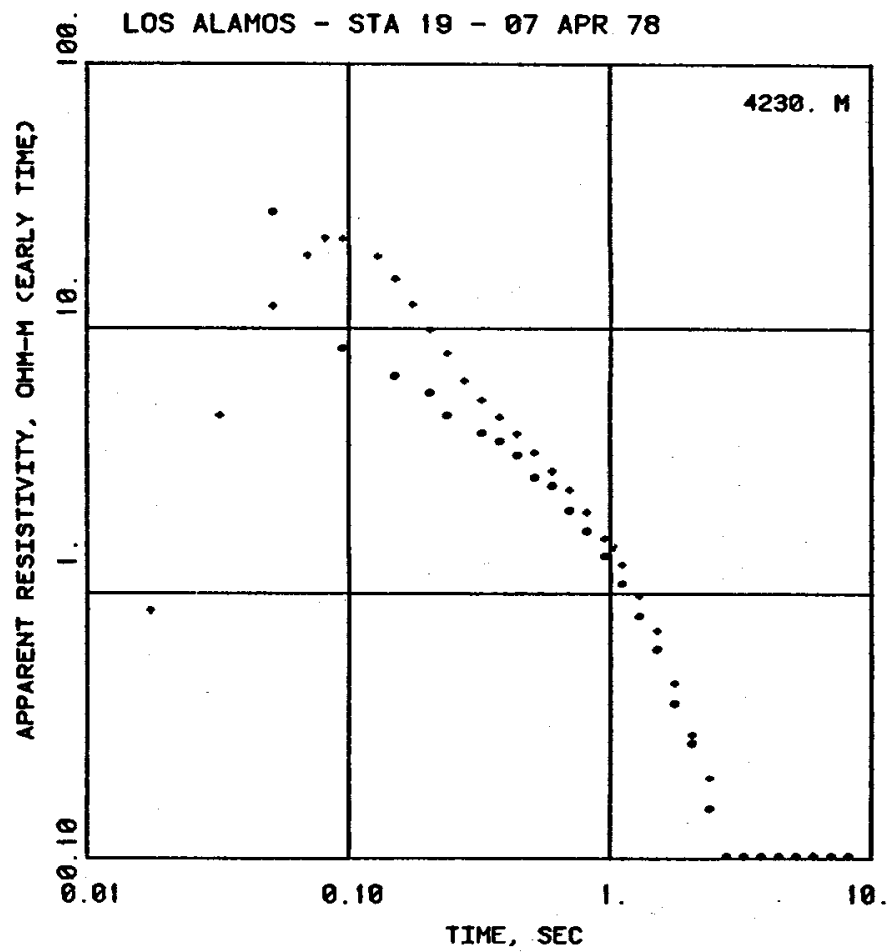



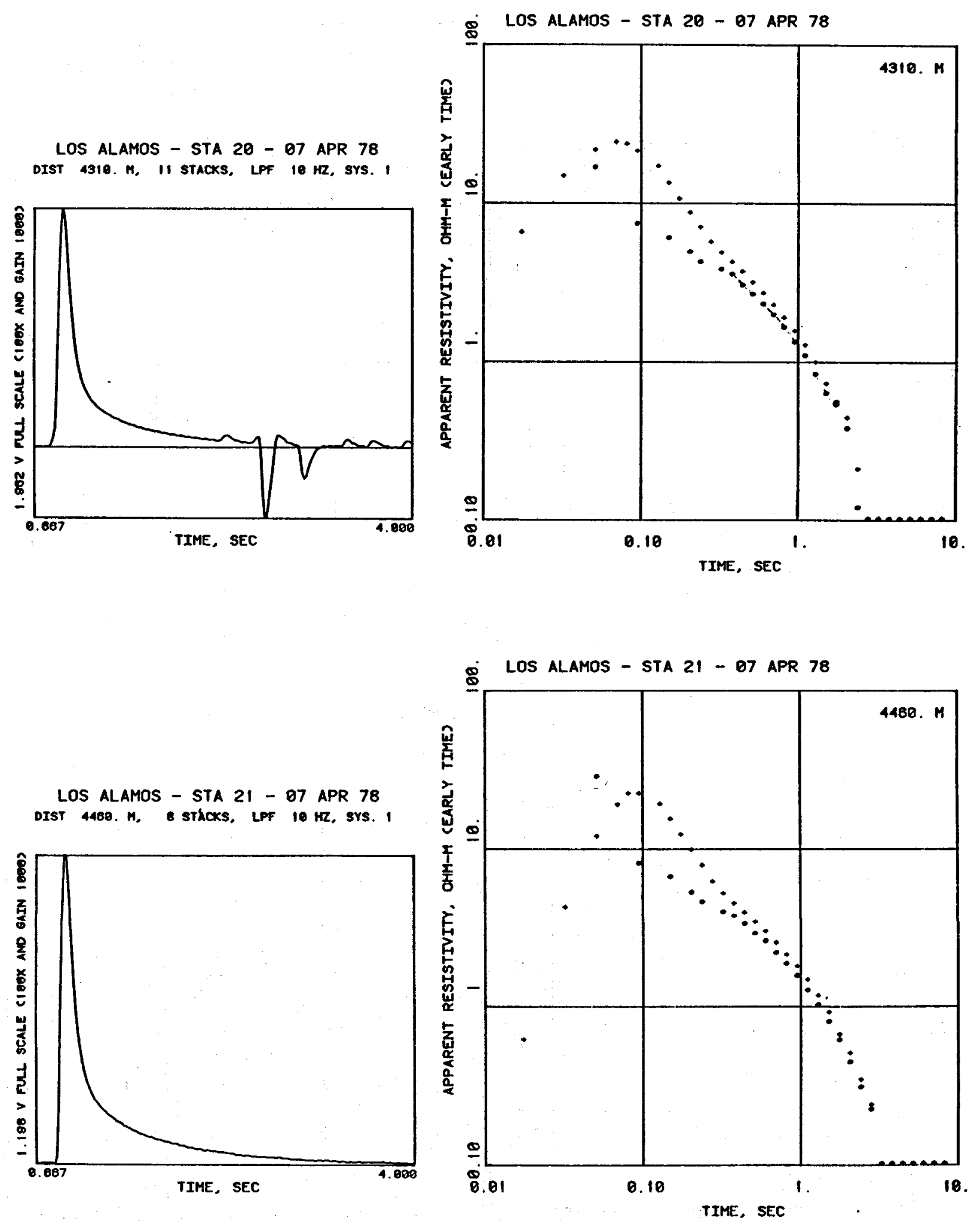

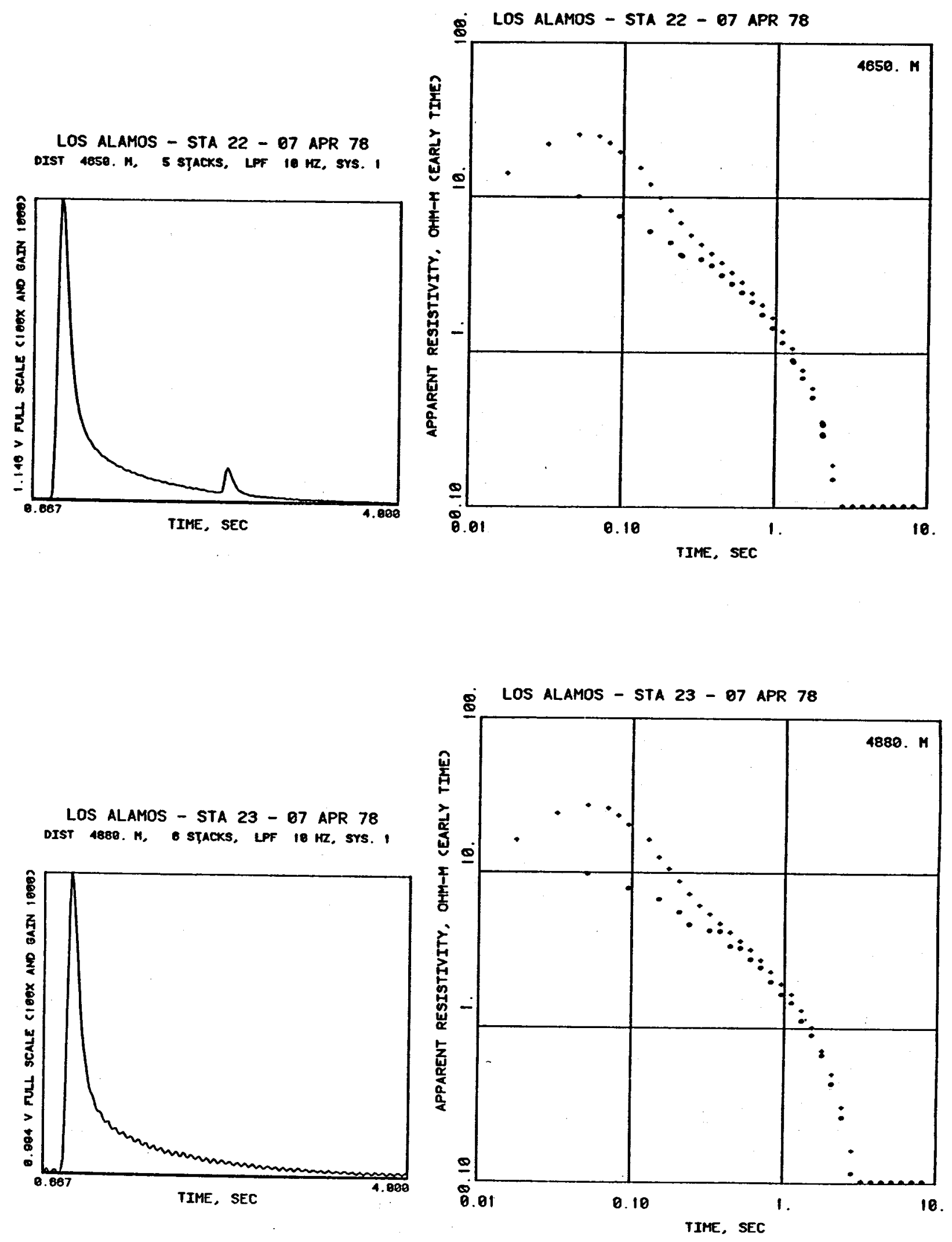

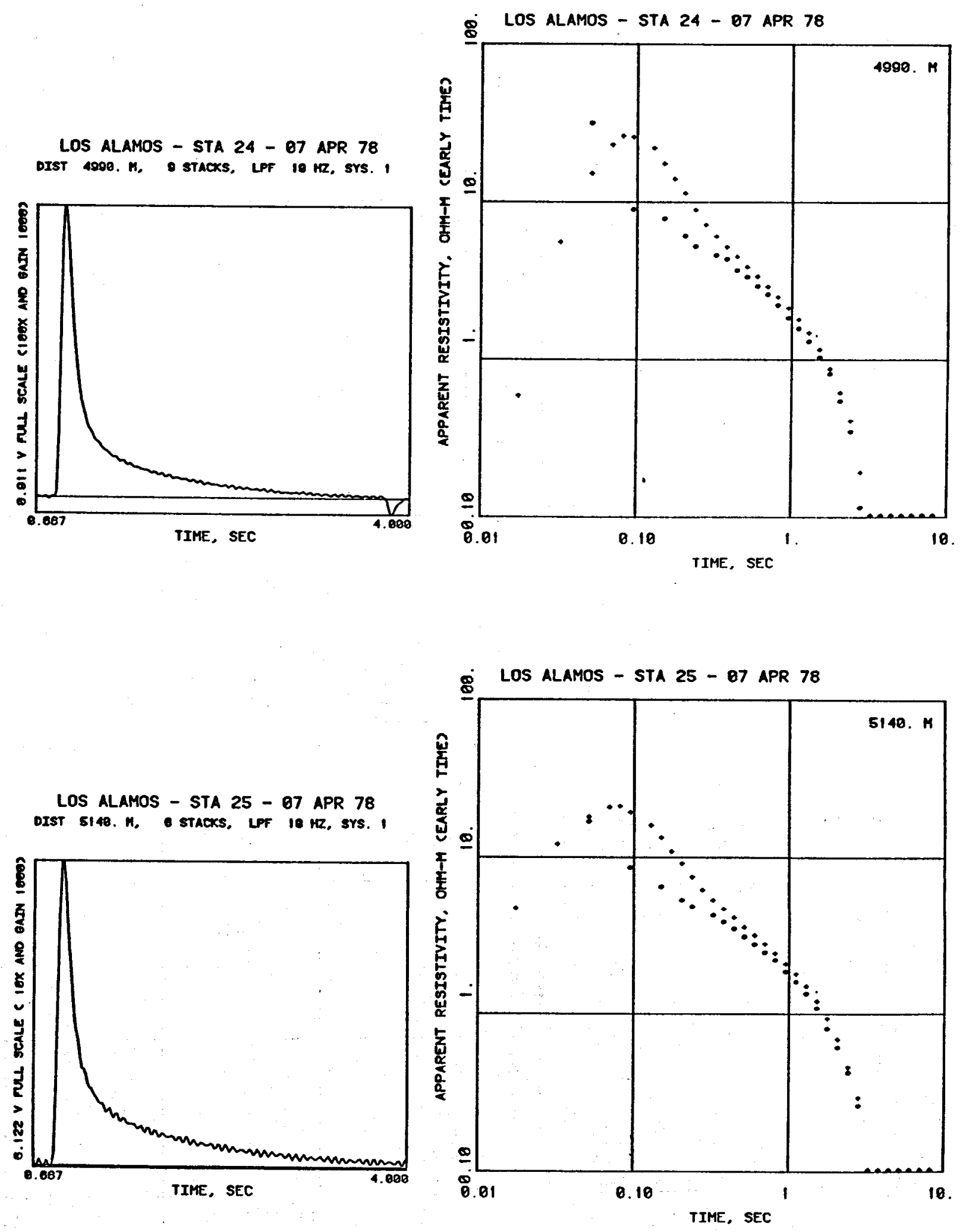

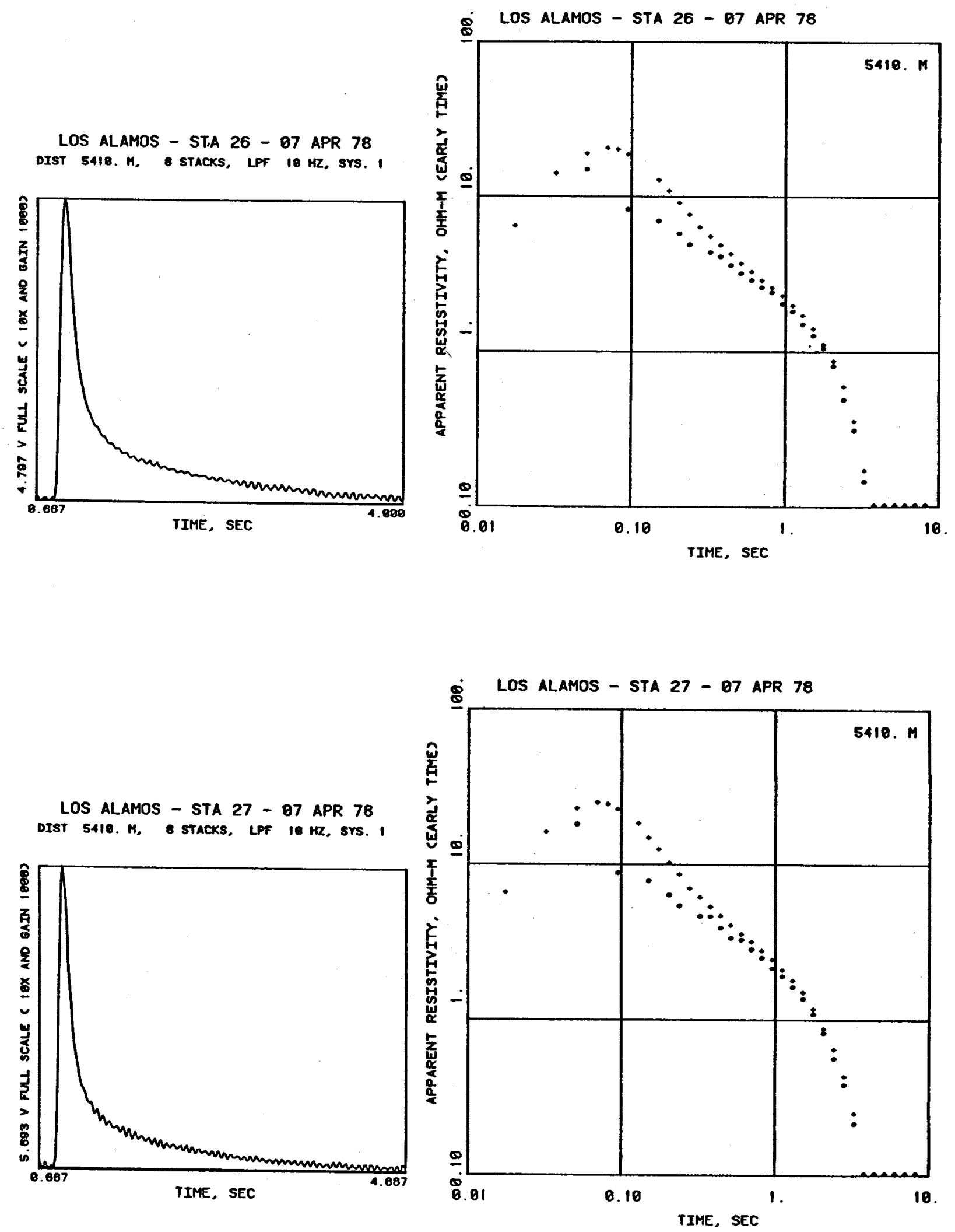

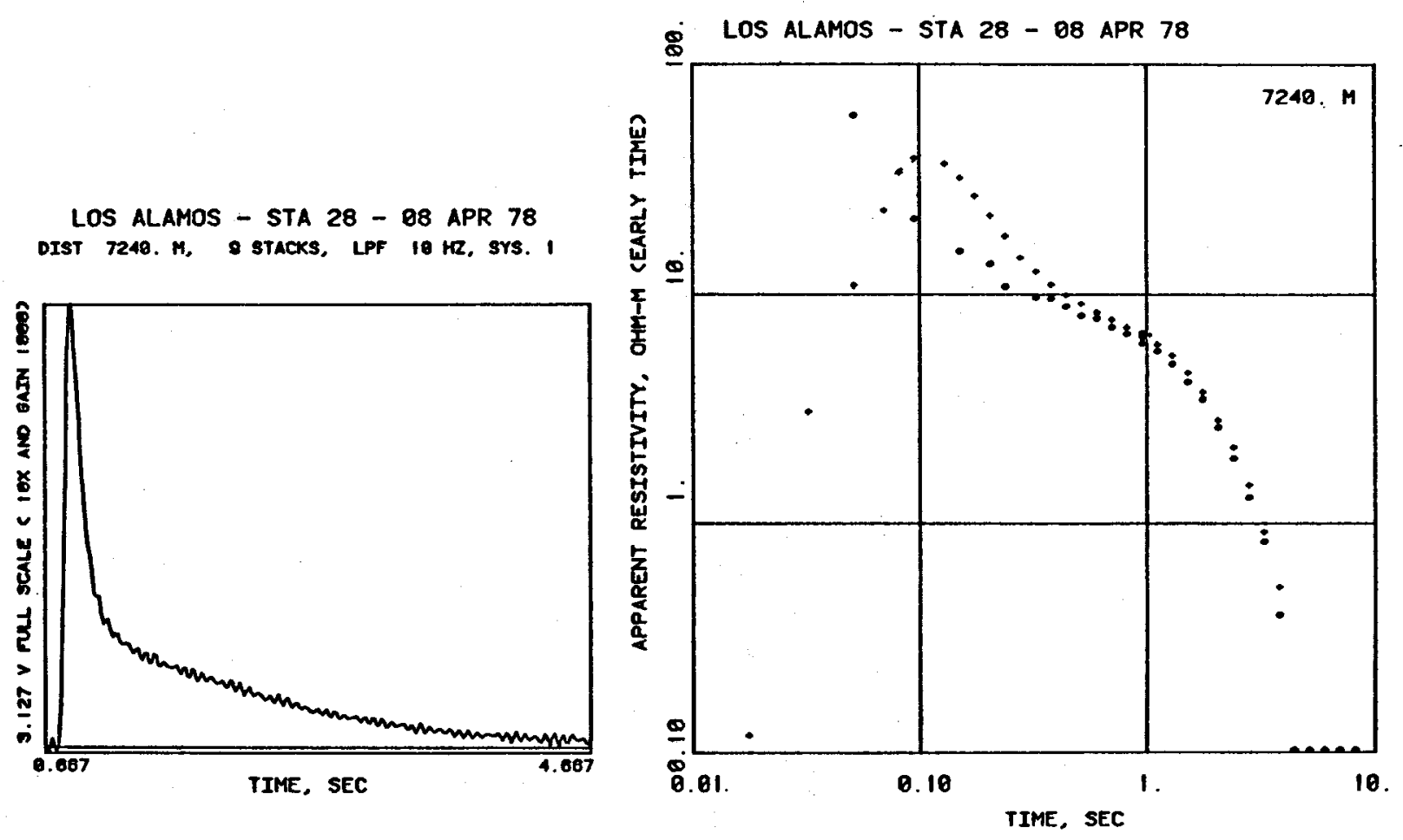

LOS ALAMOS - STA 29 - 08 APR 78 DIST 8100. $\mathrm{M}$, 5 STACKS. LPF $10 \mathrm{HZ}$, SYS. I
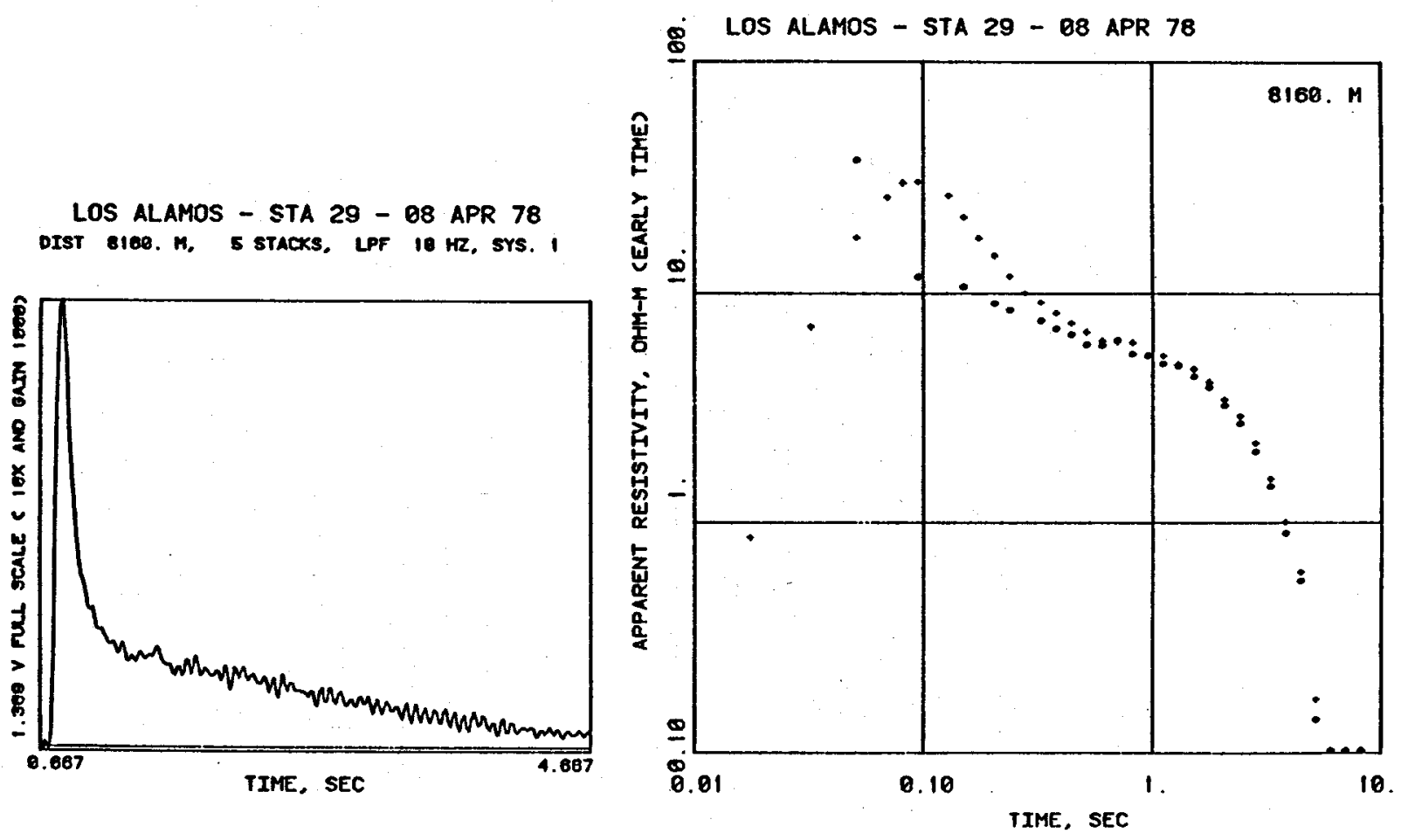

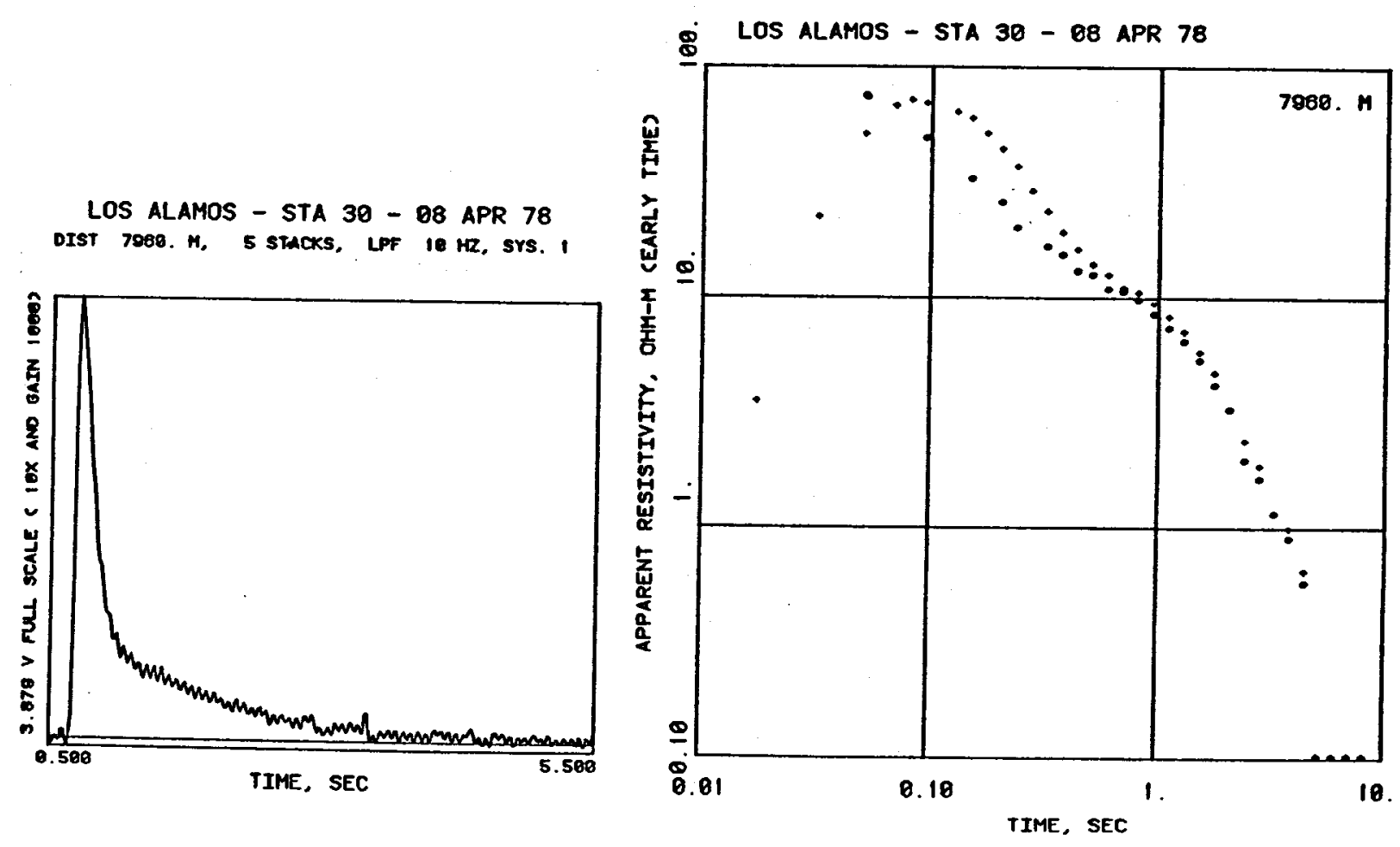

LOS ALAMOS - STA 31 - 08 APR 78 DIST 9118. M. 12 STACKS, LPF IQ Hz, SYS. I
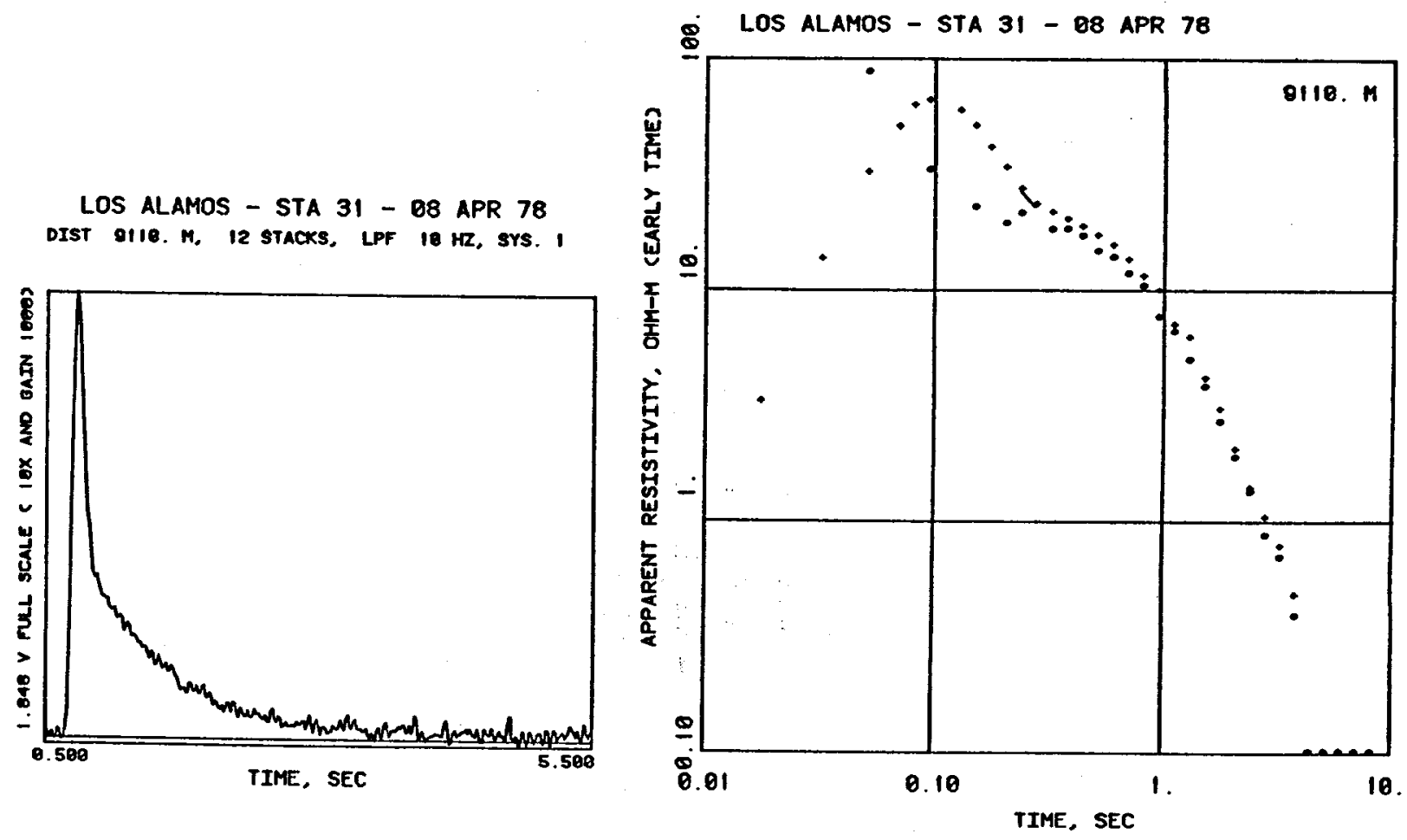
LOS ALAMOS - STA 32 - 08 APR 78

DIST 6788. M, 5 STACKS, LPF $10 \mathrm{HZ}$, SYS. I

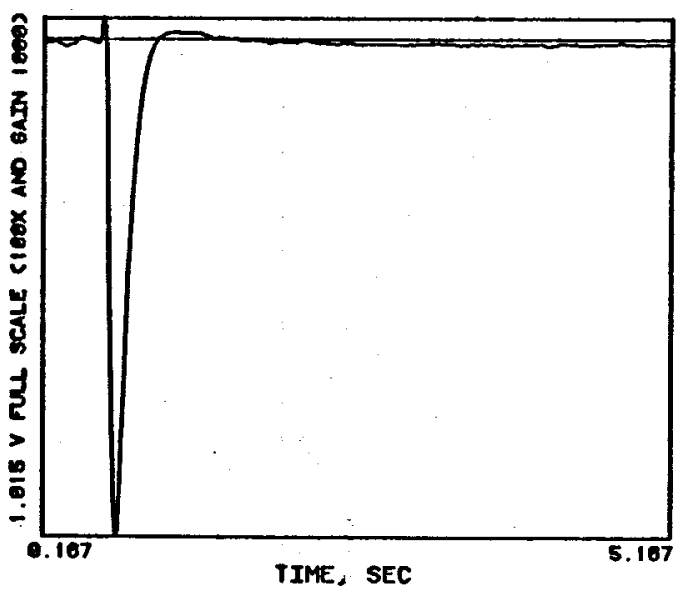

LOS ALAMOS - STA 33 - 08 APR 78 DIST 0258. N, 5 STiCKs, LPF $10 \mathrm{HZ}$, SYS. I
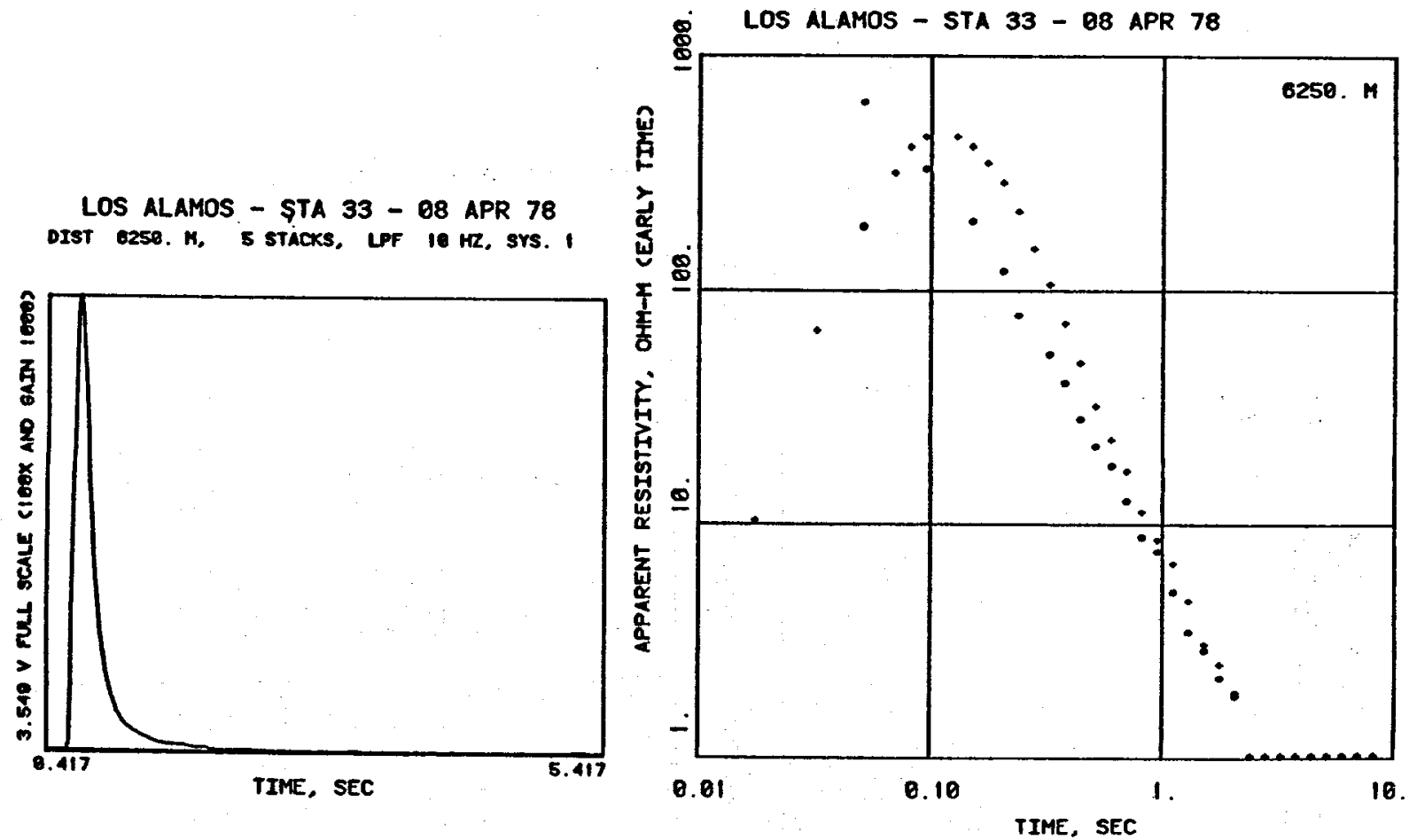

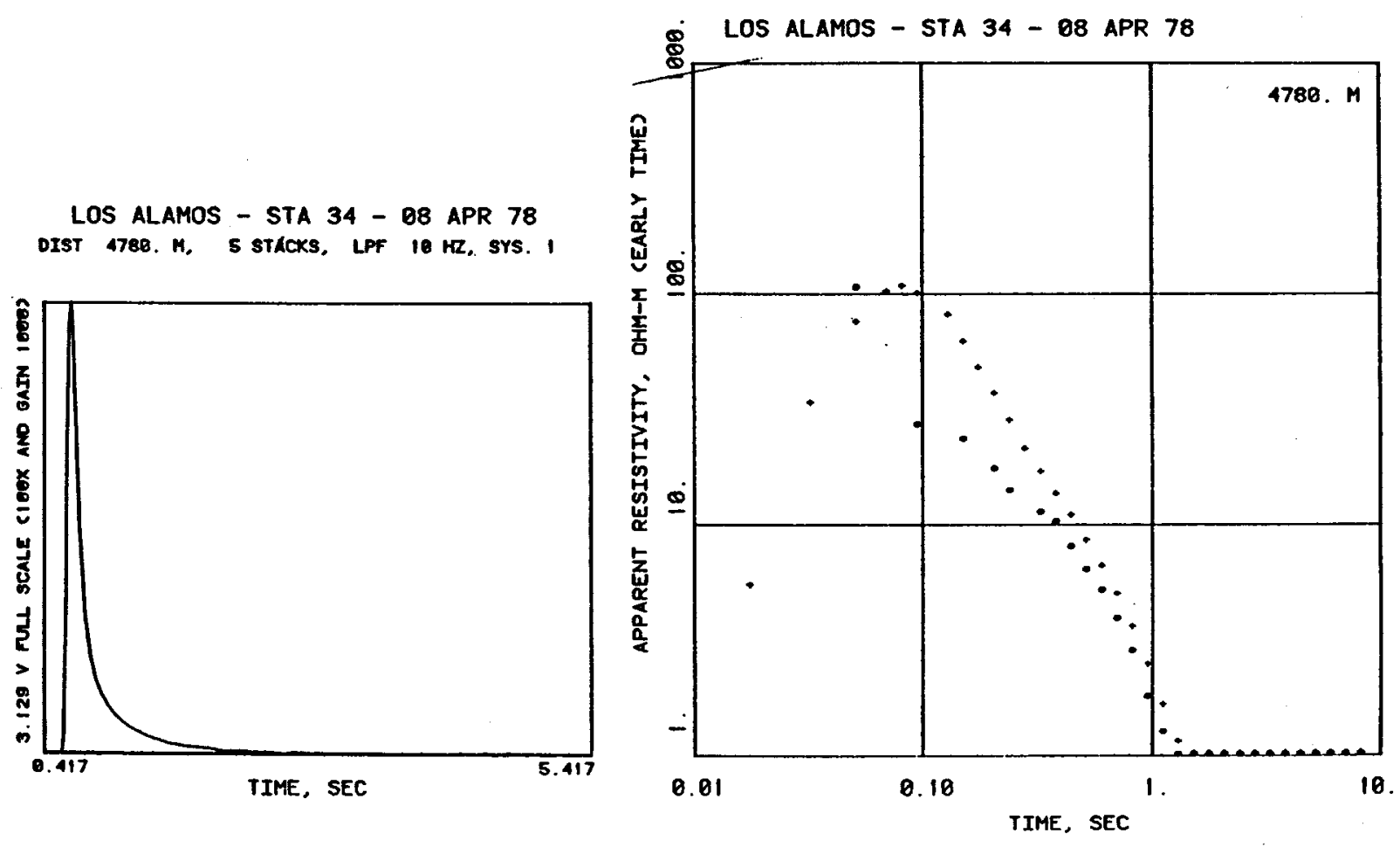

LOS ALAMOS - STA 35 - 09 APR 78 DIST 2870. M, 5 STACKS, LPF $10 \mathrm{MR}$, SYS. I
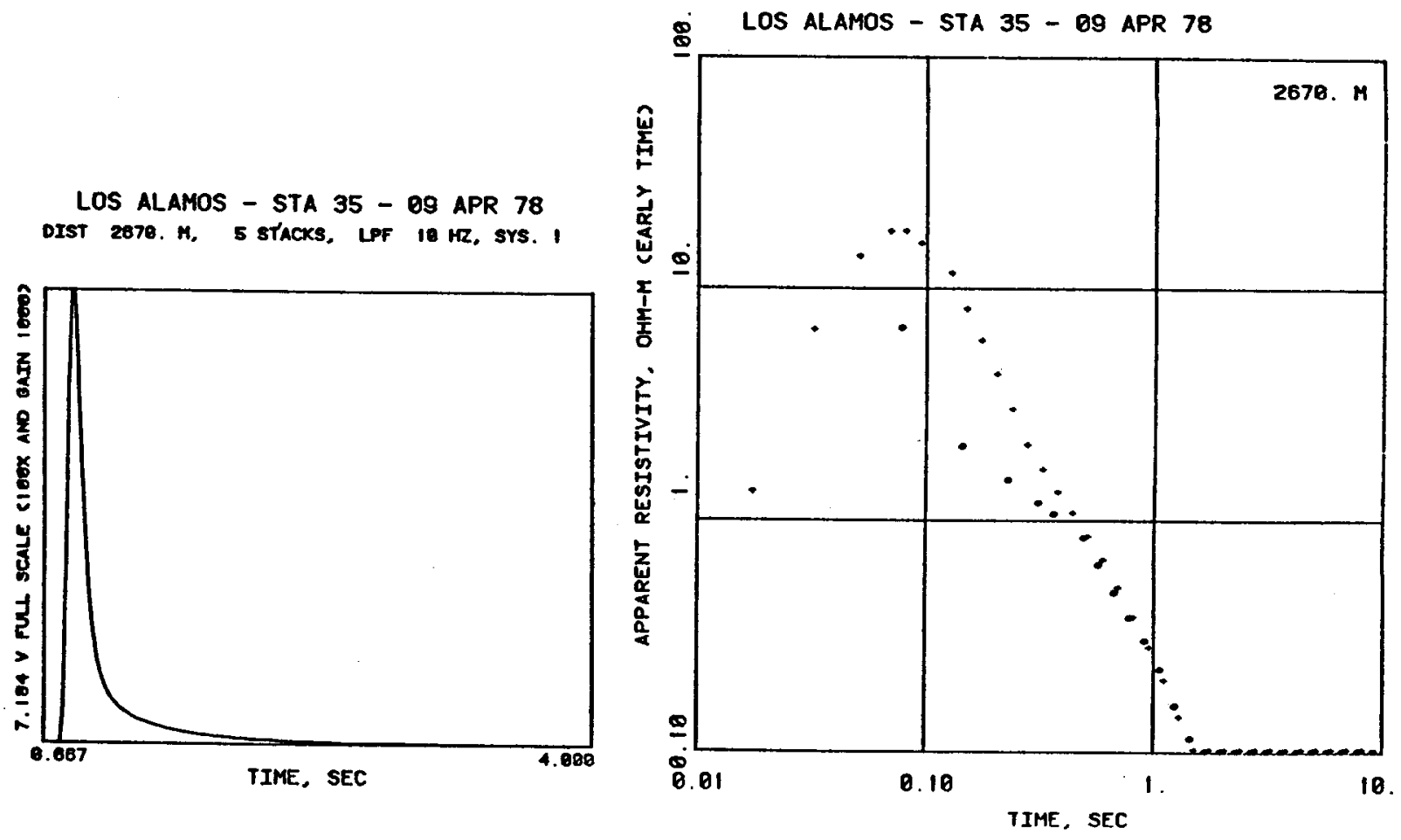
LOS ALAMOS - STA 36 - 09 APR 78 DIST 2420. M, 5 STACKS, LPF $10 \mathrm{HZ}$. SYS. I

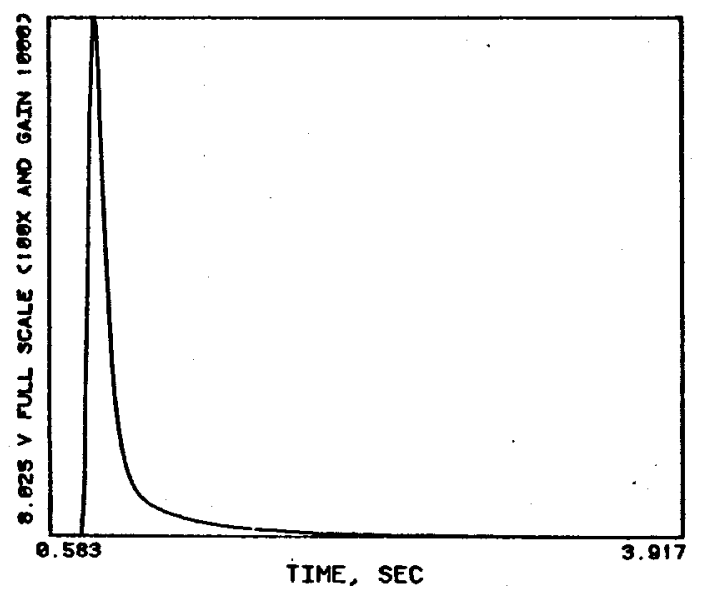

LOS ALAMOS - STA 37 - 99 APR 78 DIST 2408. M, S stACKS, LPF $10 \mathrm{MZ}$, SYS. I

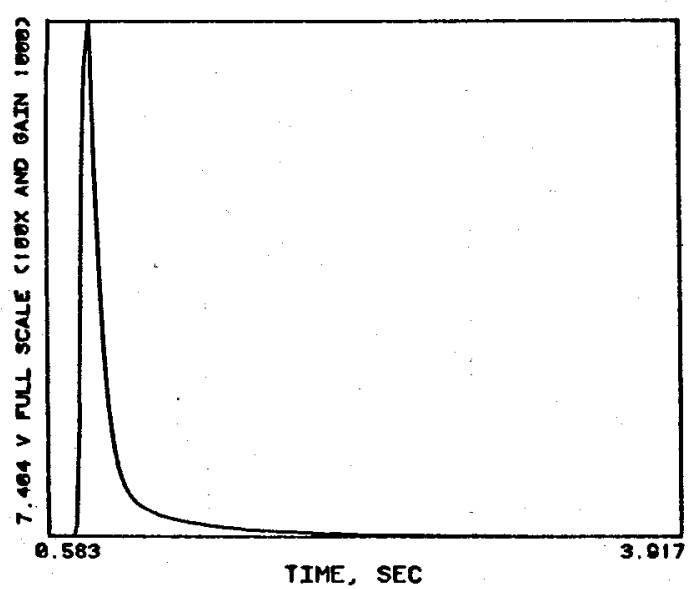

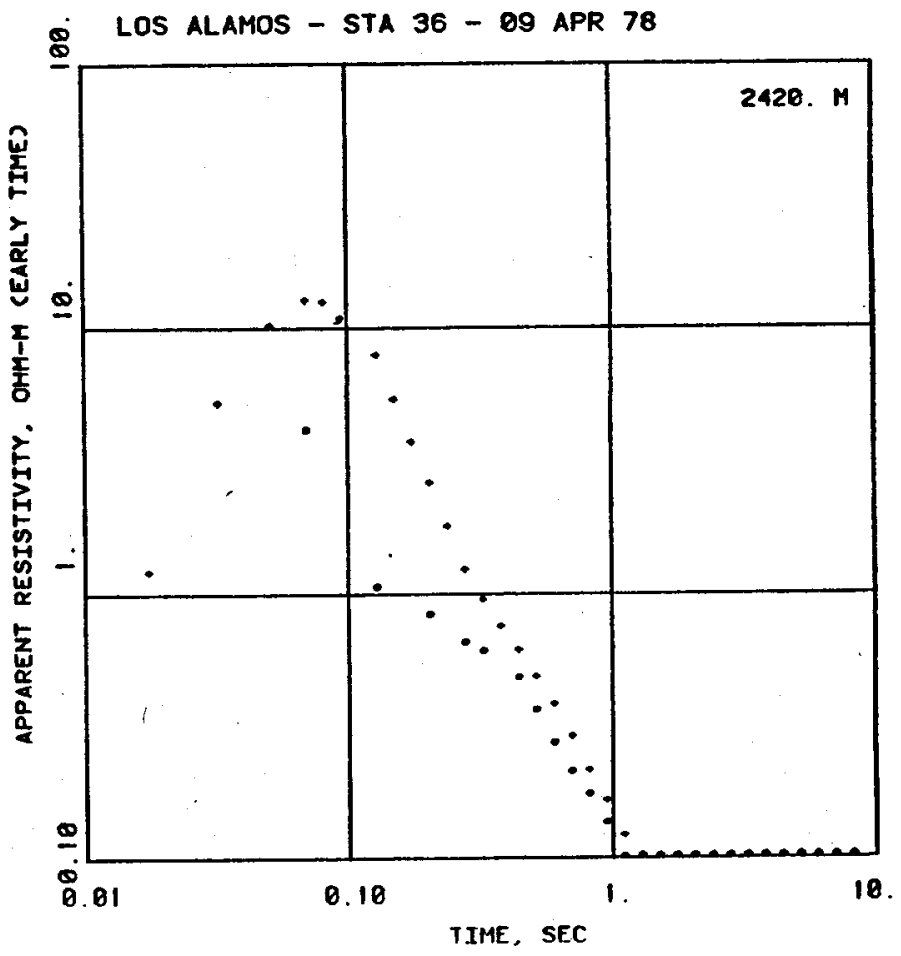

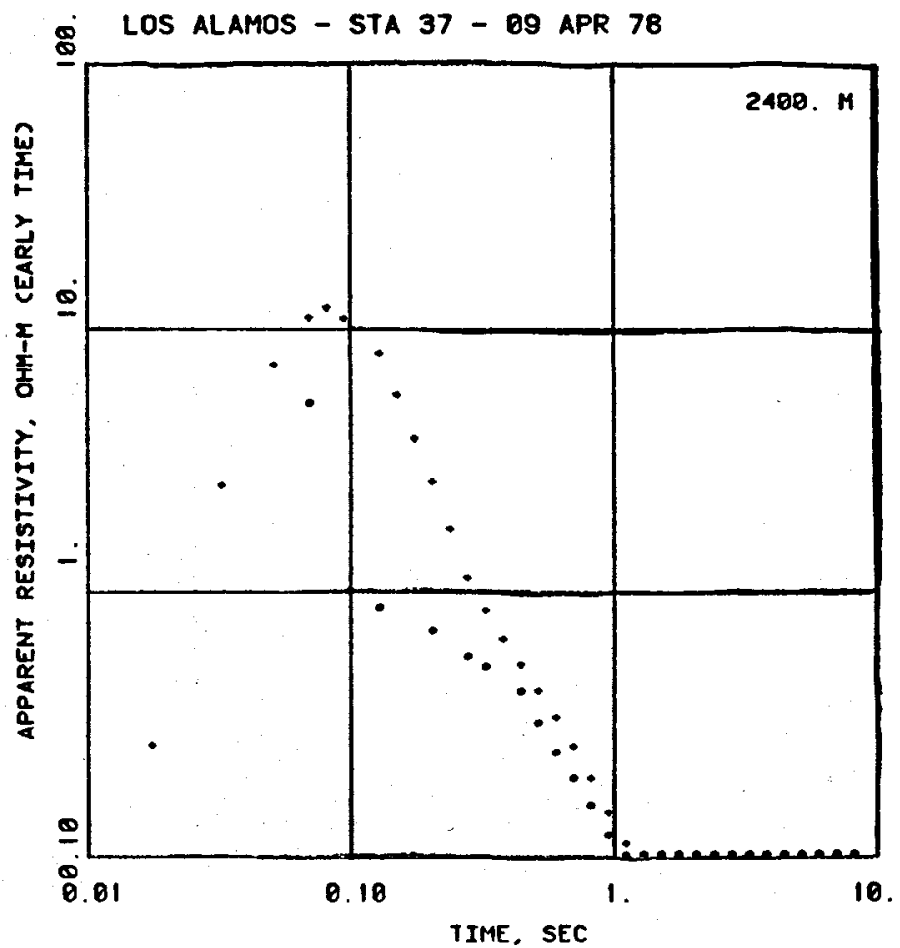



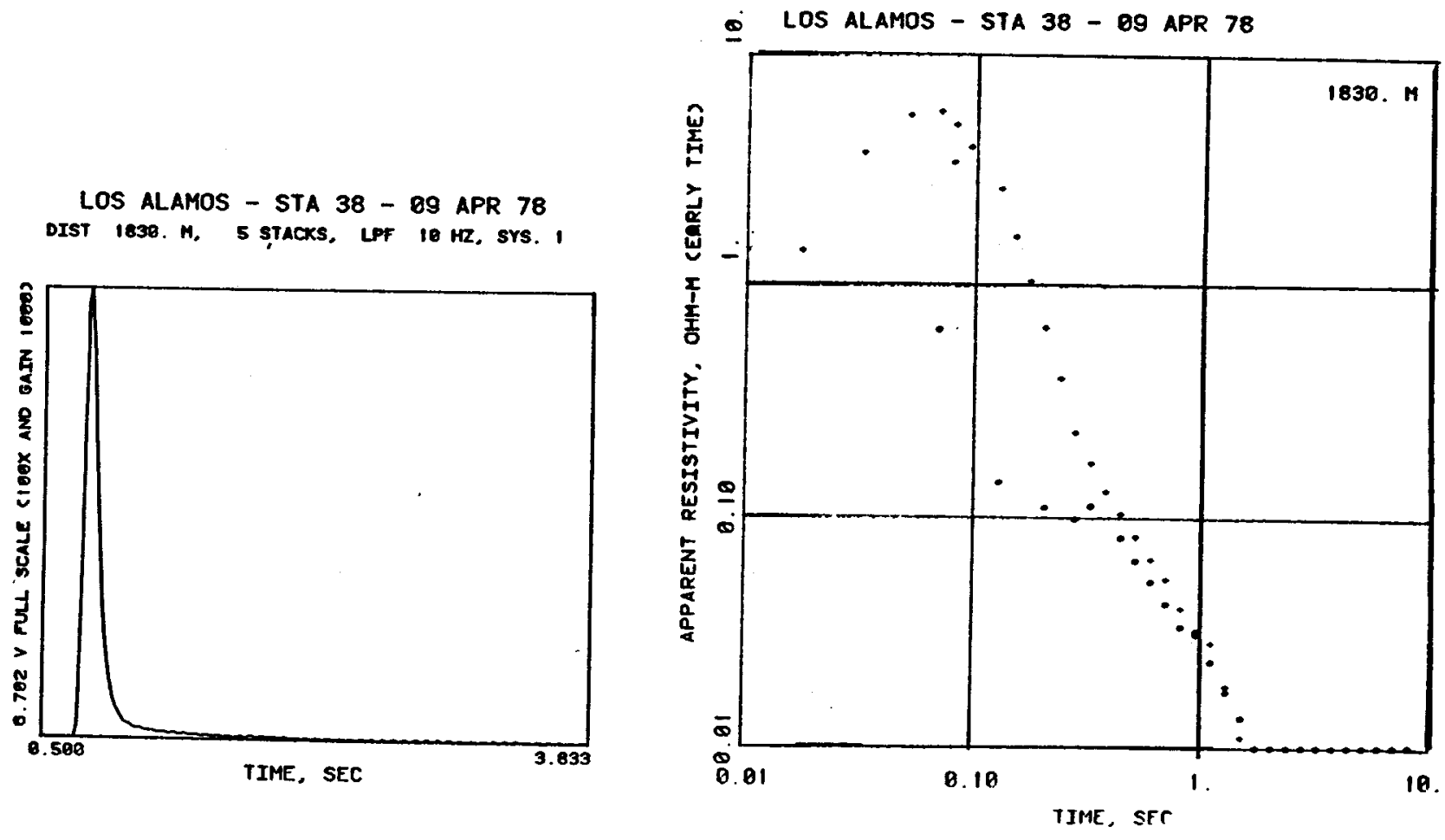

LOS ALAMOS - STA 39 - 69 APR 78 DIST 3000. M, O STACKS, LPF $10 \mathrm{kz}$, SYS. I
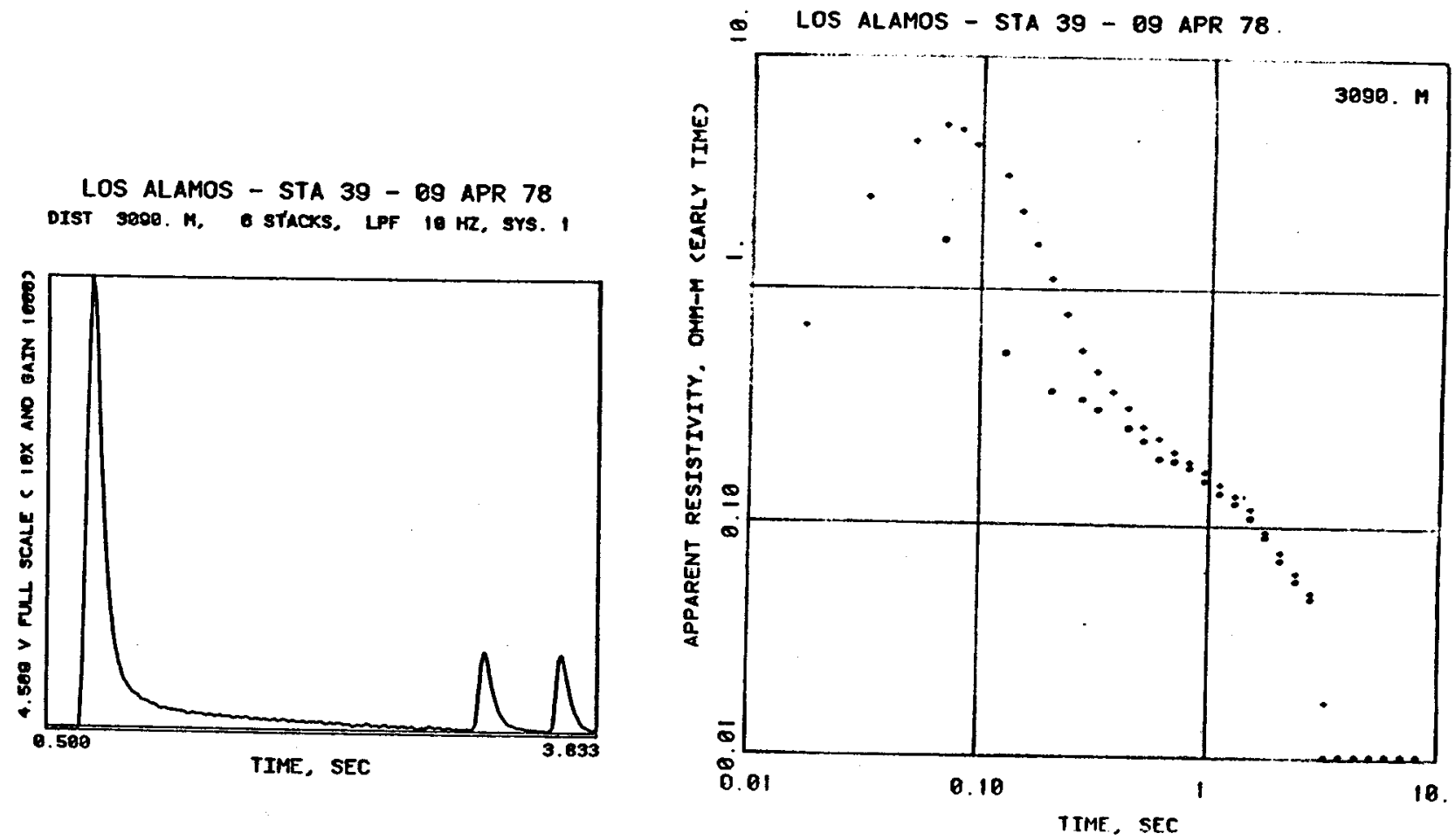
LOS ALAMOS - STA 10 - 99 APR 78 DIST s510. $M, 5$ STACKS, LPF $10 \mathrm{~Hz}$. SYS. I

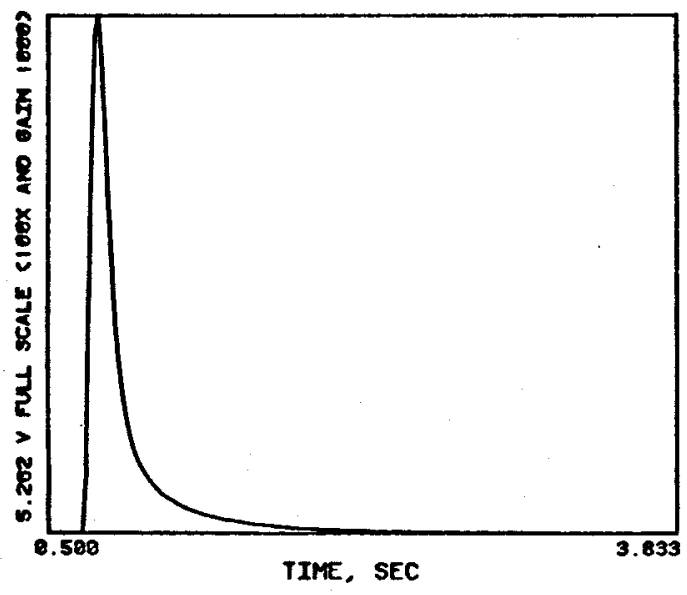

LOS ALAMOS - STA 41 - 99 APR 78 DIST 4030. M, 5 sTACKS, LPF $10 \mathrm{MR}$. STS. I

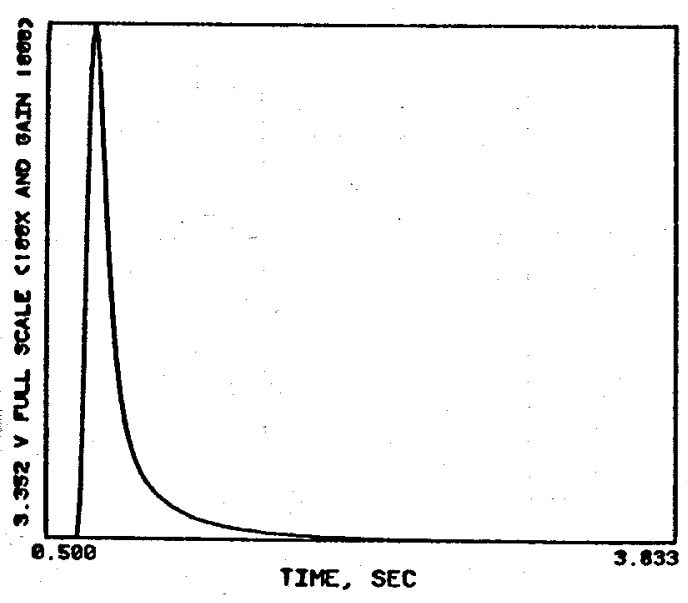

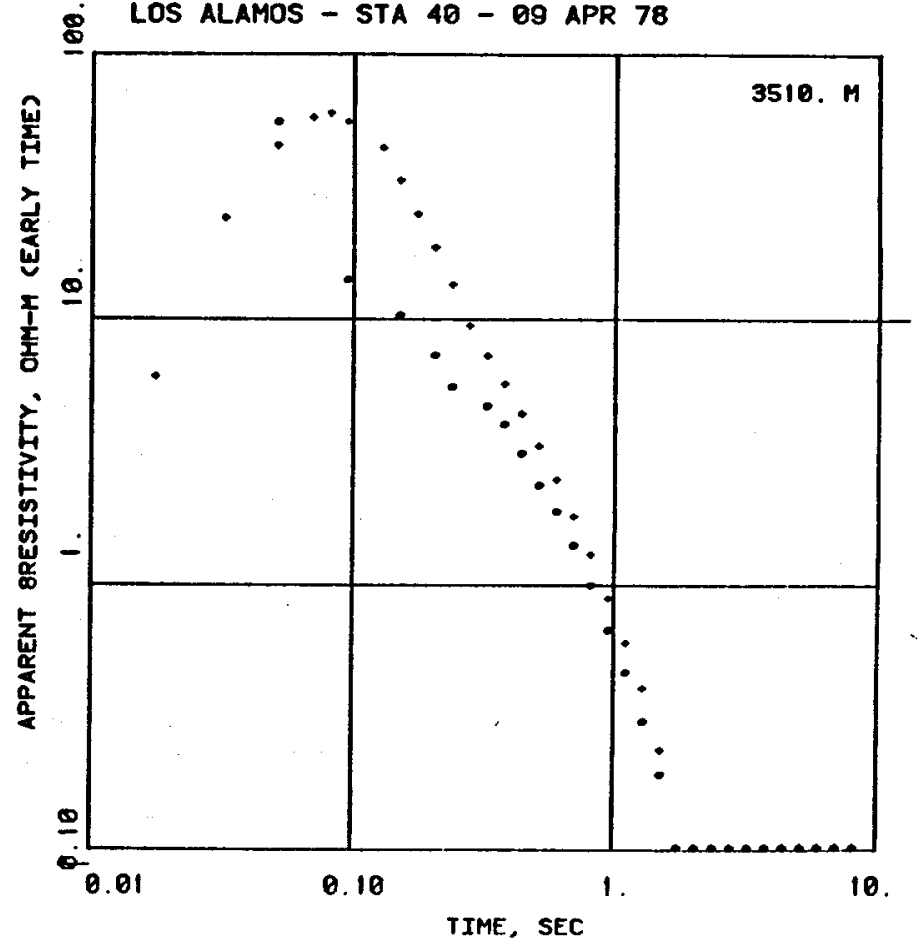

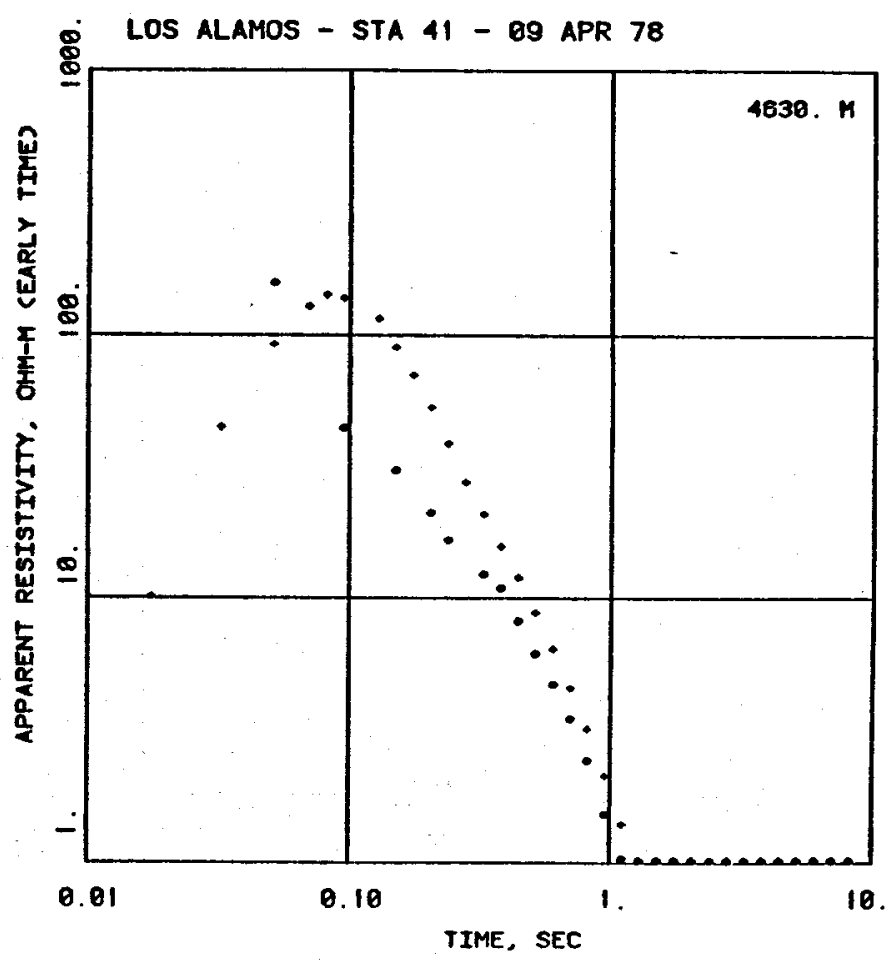


LOS ALAMOS - STA 42 - 09 APR 78 DIST 5530. M, 5 sTACKS, LPF $10 \mathrm{HZ}$, SYS.

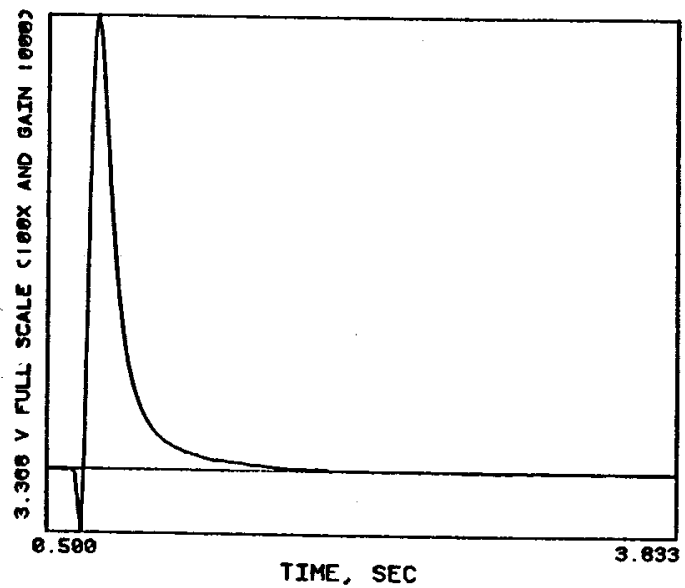

LOS ALAMOS - STA 43 - 11 APR 78 DIST 9450. $M, 11$ STACKS, LPF $10 \mathrm{HZ}$, SYS,

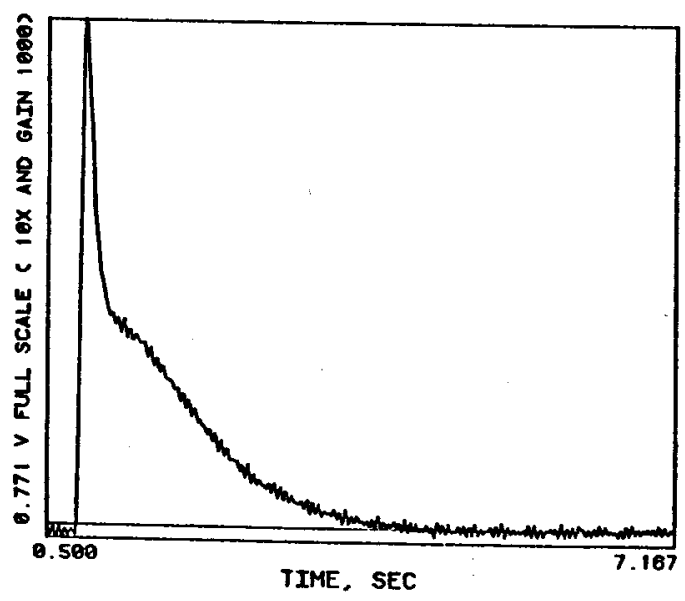

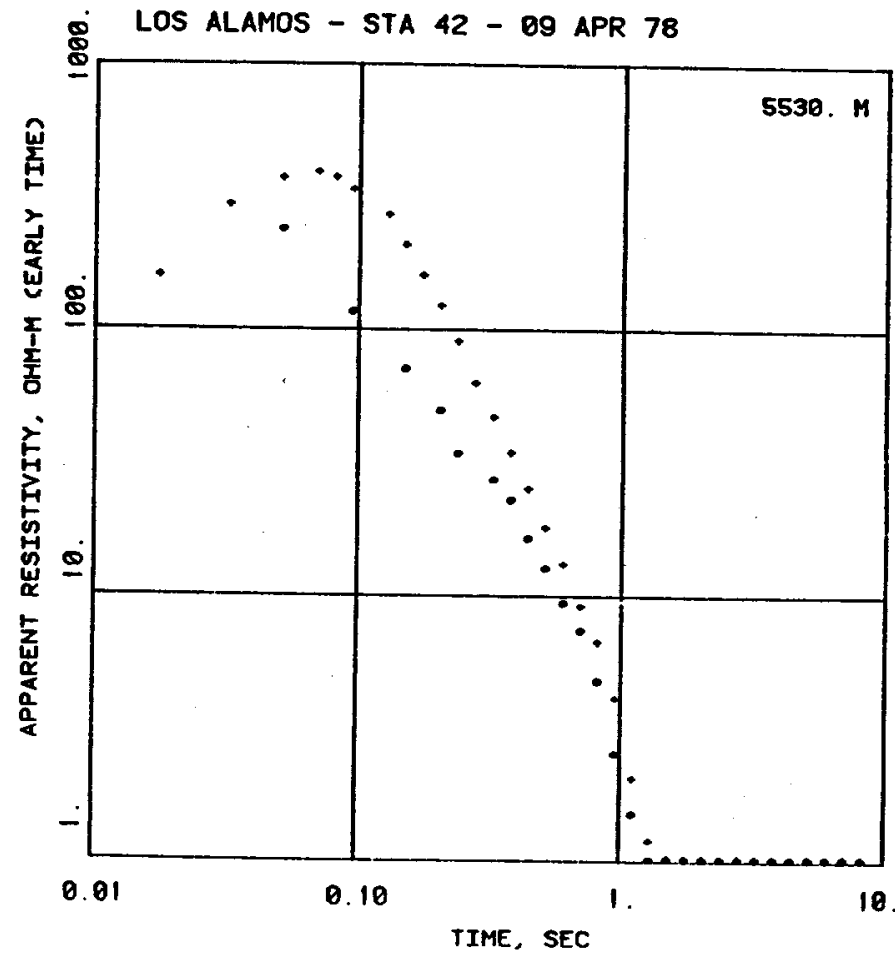

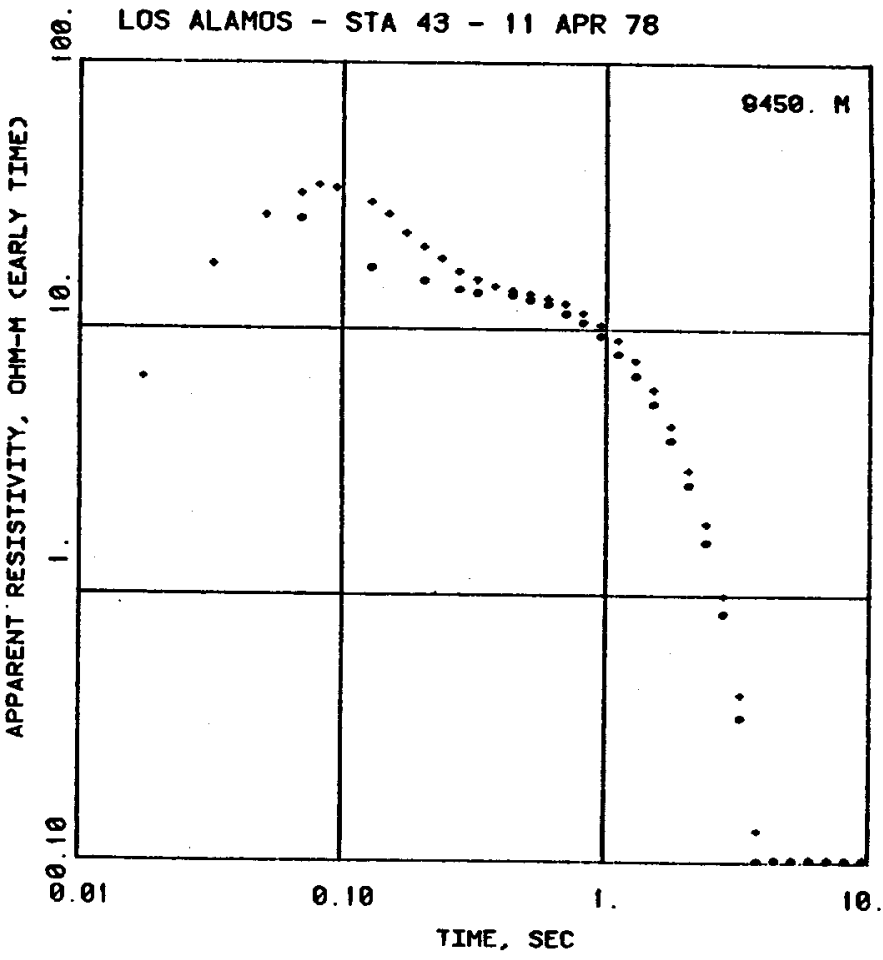


LOS ALAMOS - STA 44 - 11 APR 78 DIST 10180. $\mathrm{H}, 12$ STACKS, LPF $10 \mathrm{HZ}$, SYS. I

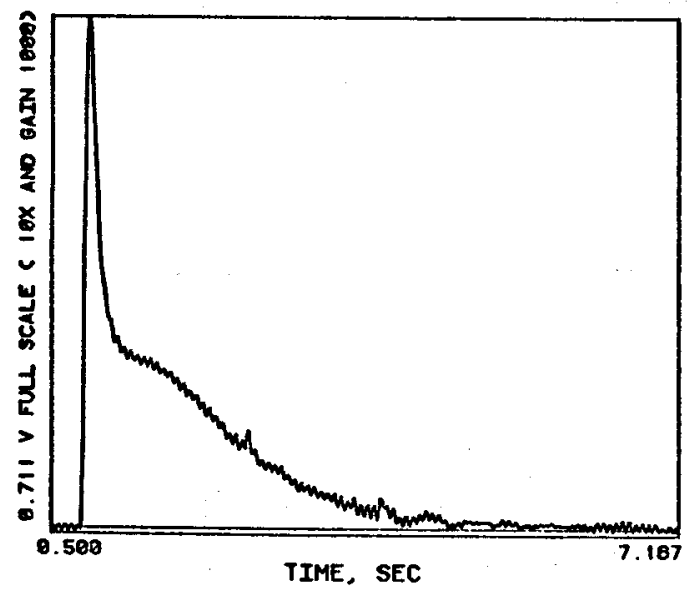

LOS ALAMOS - STA 45 - 10 APR 78 DIST 11500. M, 14 STACKs, LPF $10 \mathrm{kR}$, SYS. I

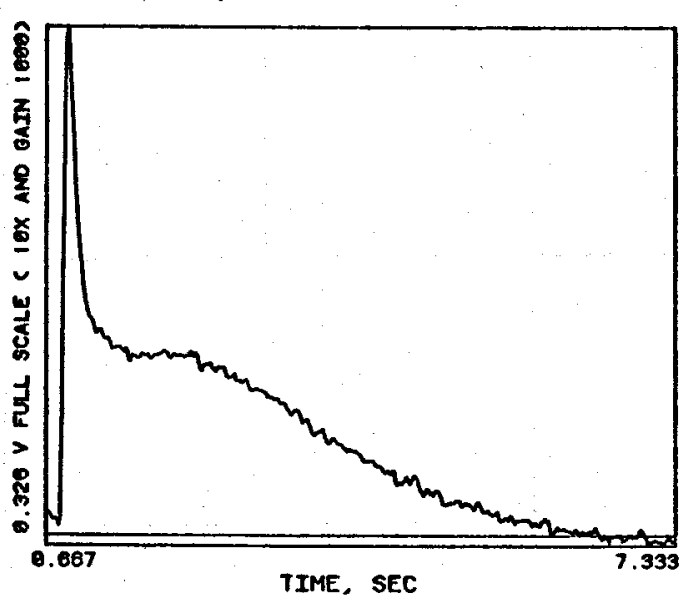

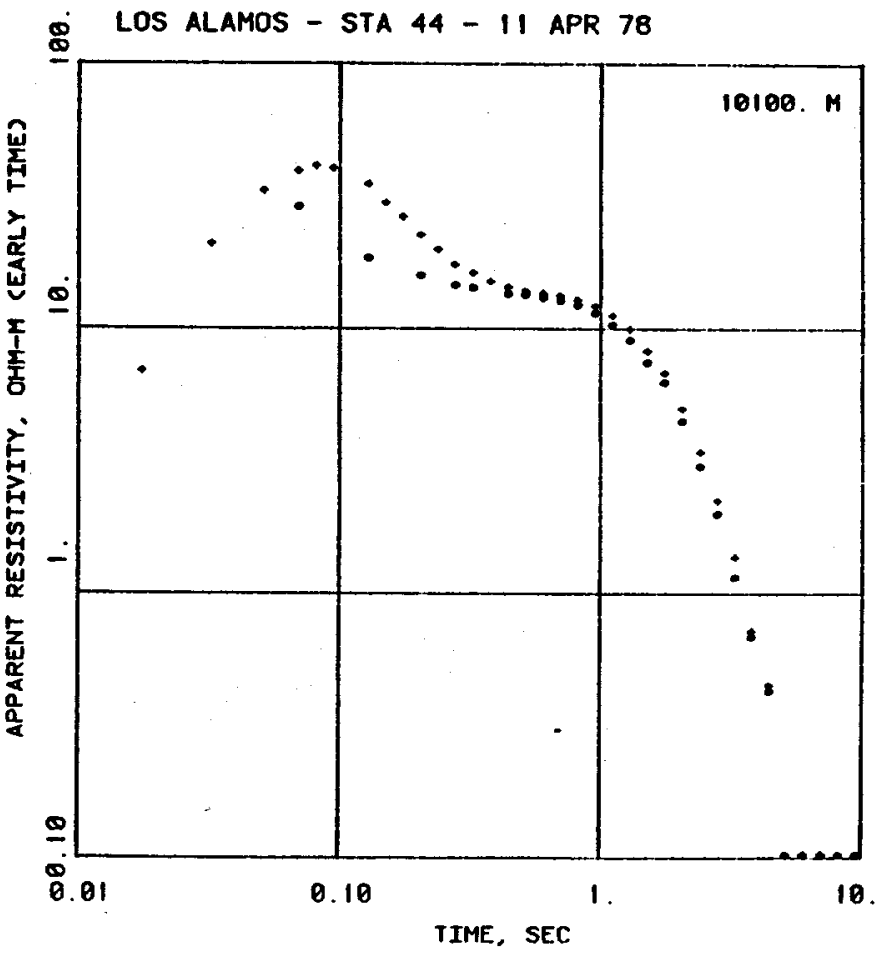

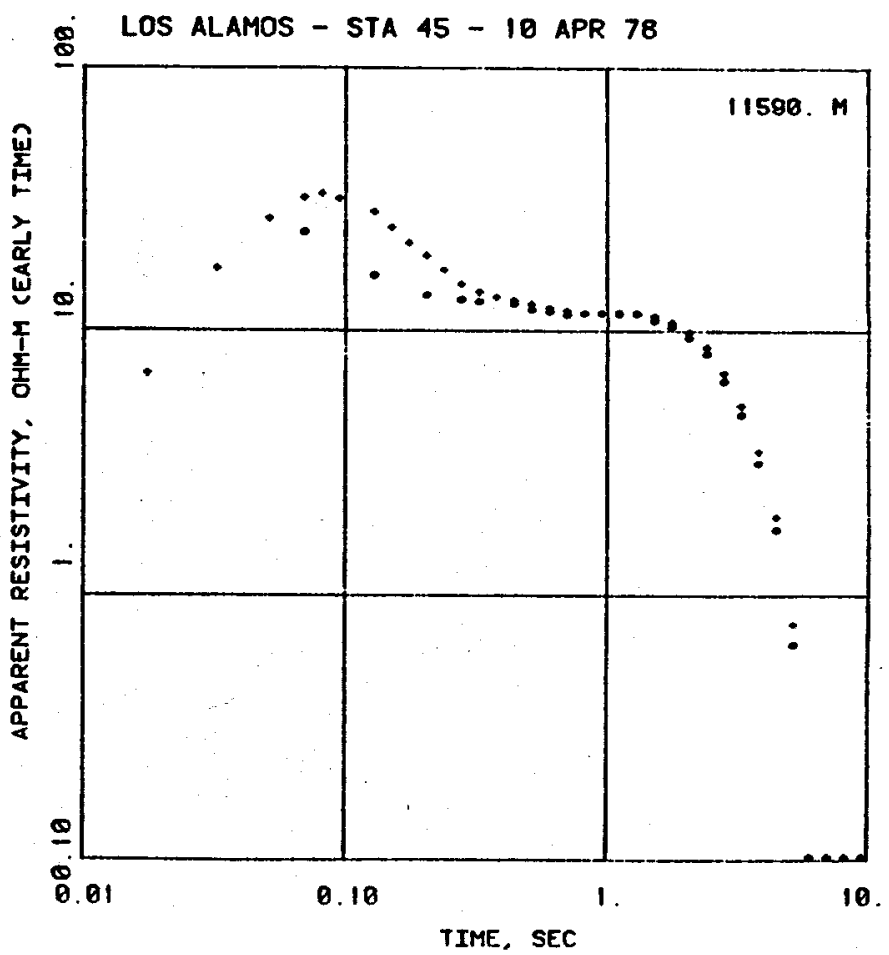


LOS ALAMOS - STA 46 - 10 APR 78 DIST 12480. M, is STACKS, LPF 10 RR, SYS. I

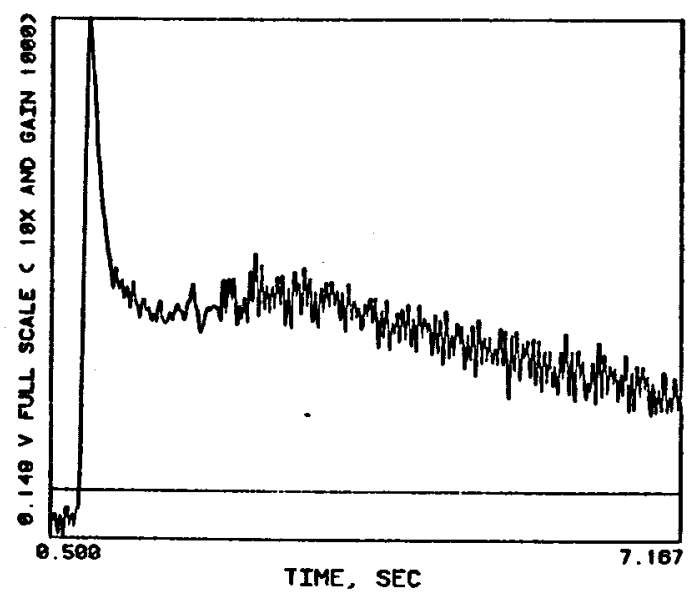

LOS ALAMOS - STA 47 - 10 APR 78 DIST 1328B. $n$, 18 STACKS, LPF $18 \mathrm{HZ}$, SYS. I

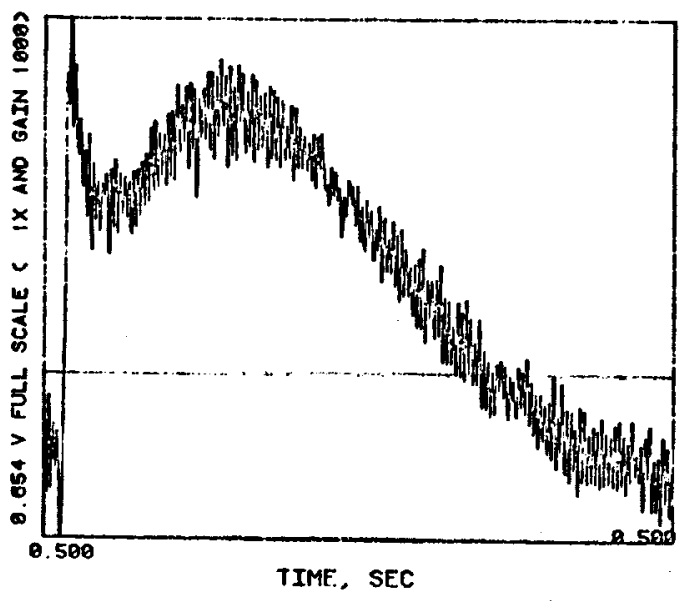

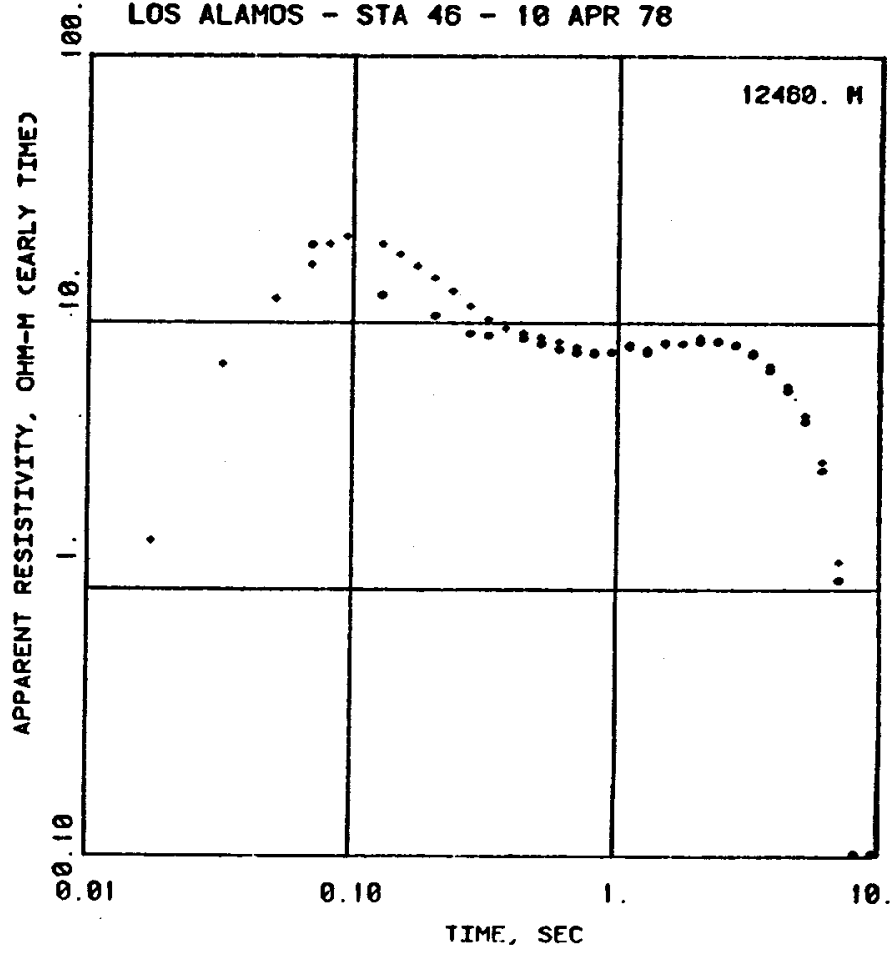

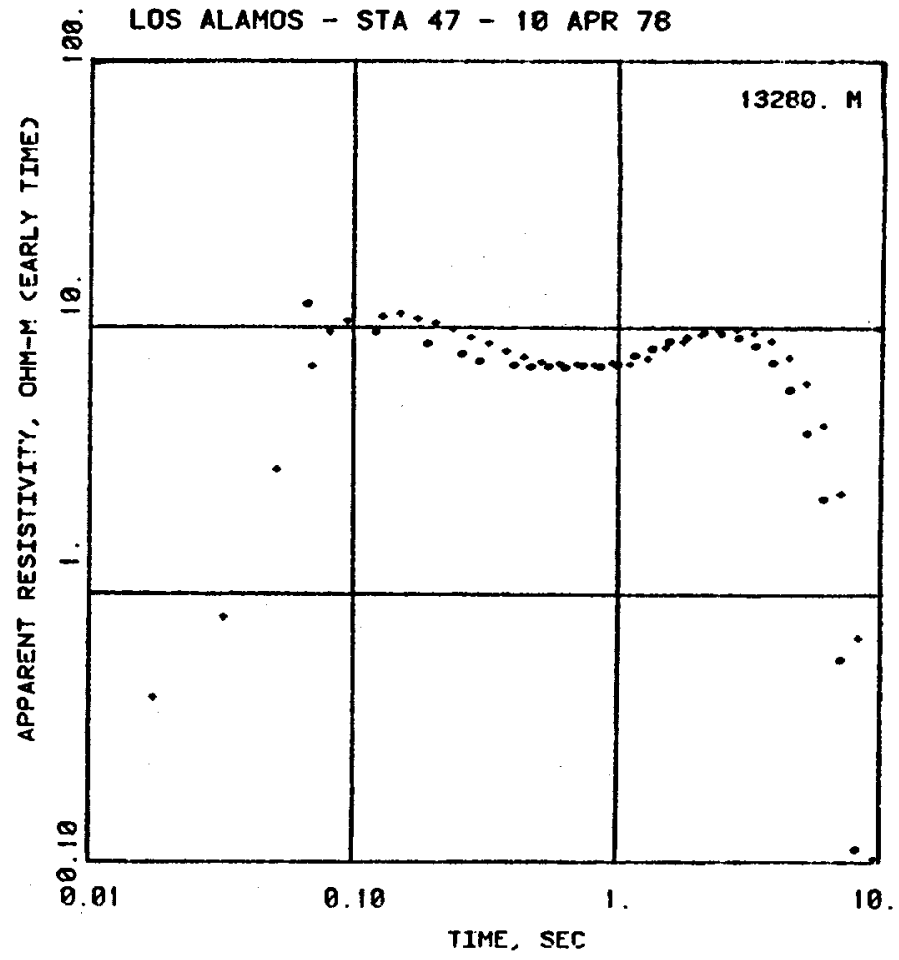



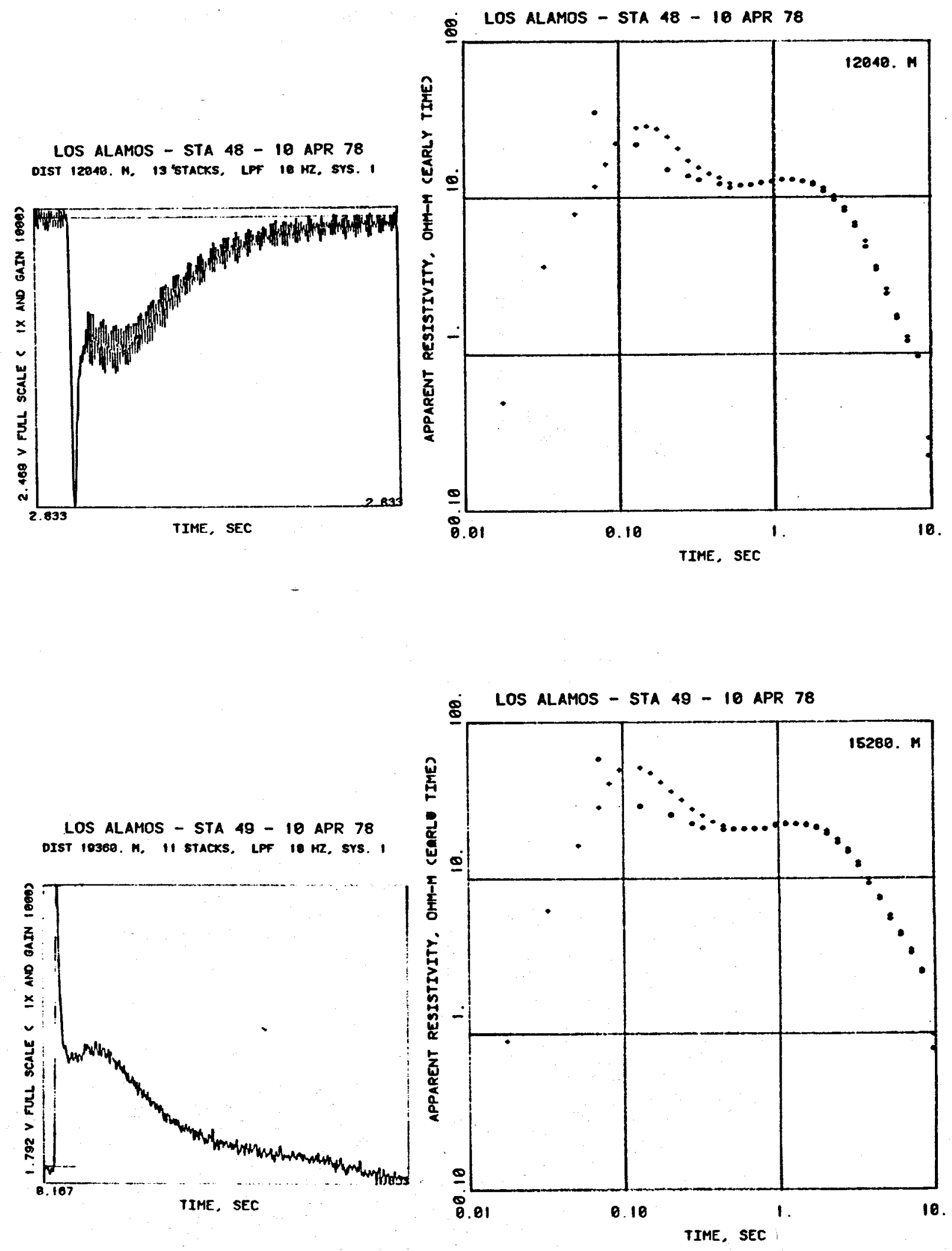


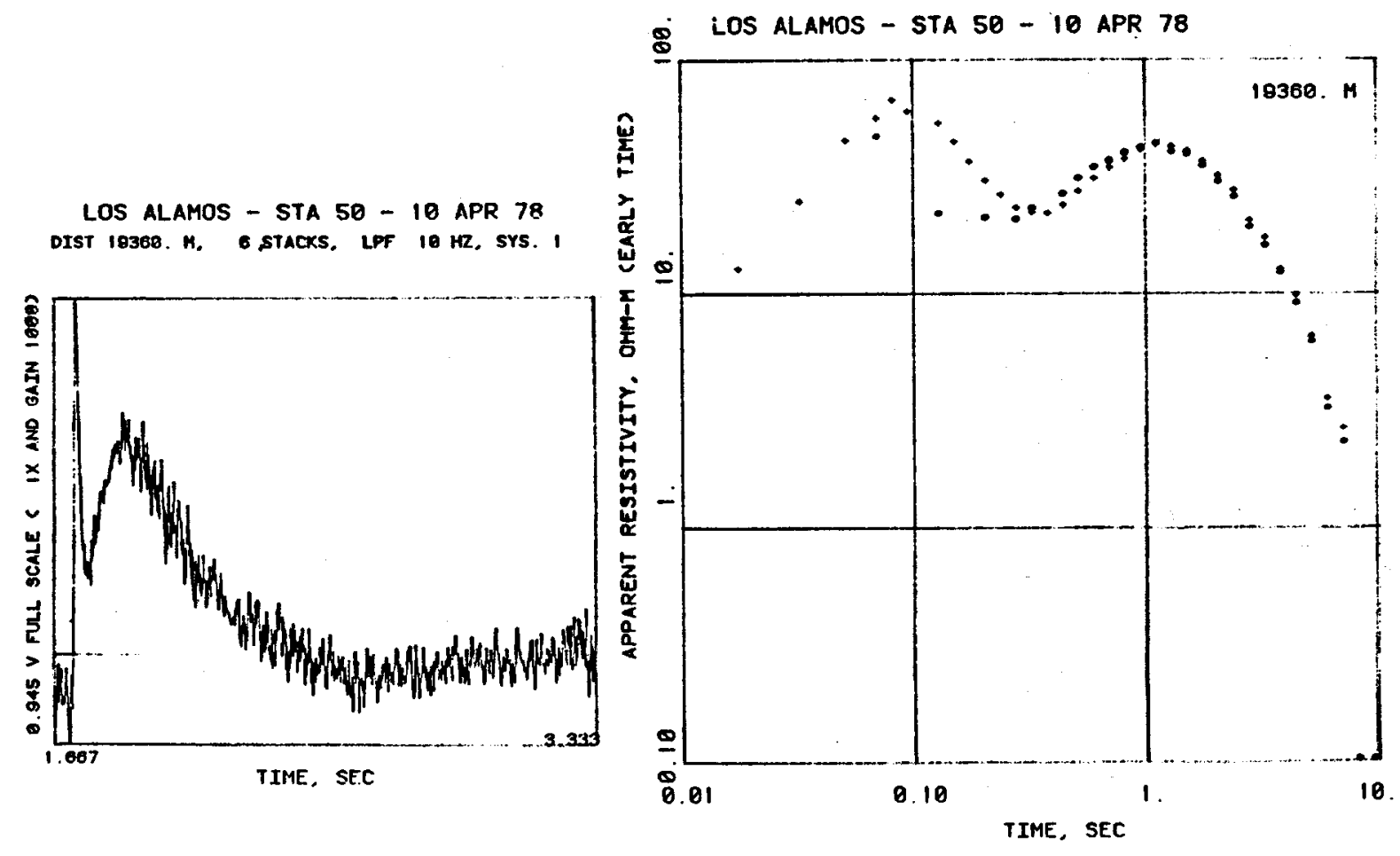




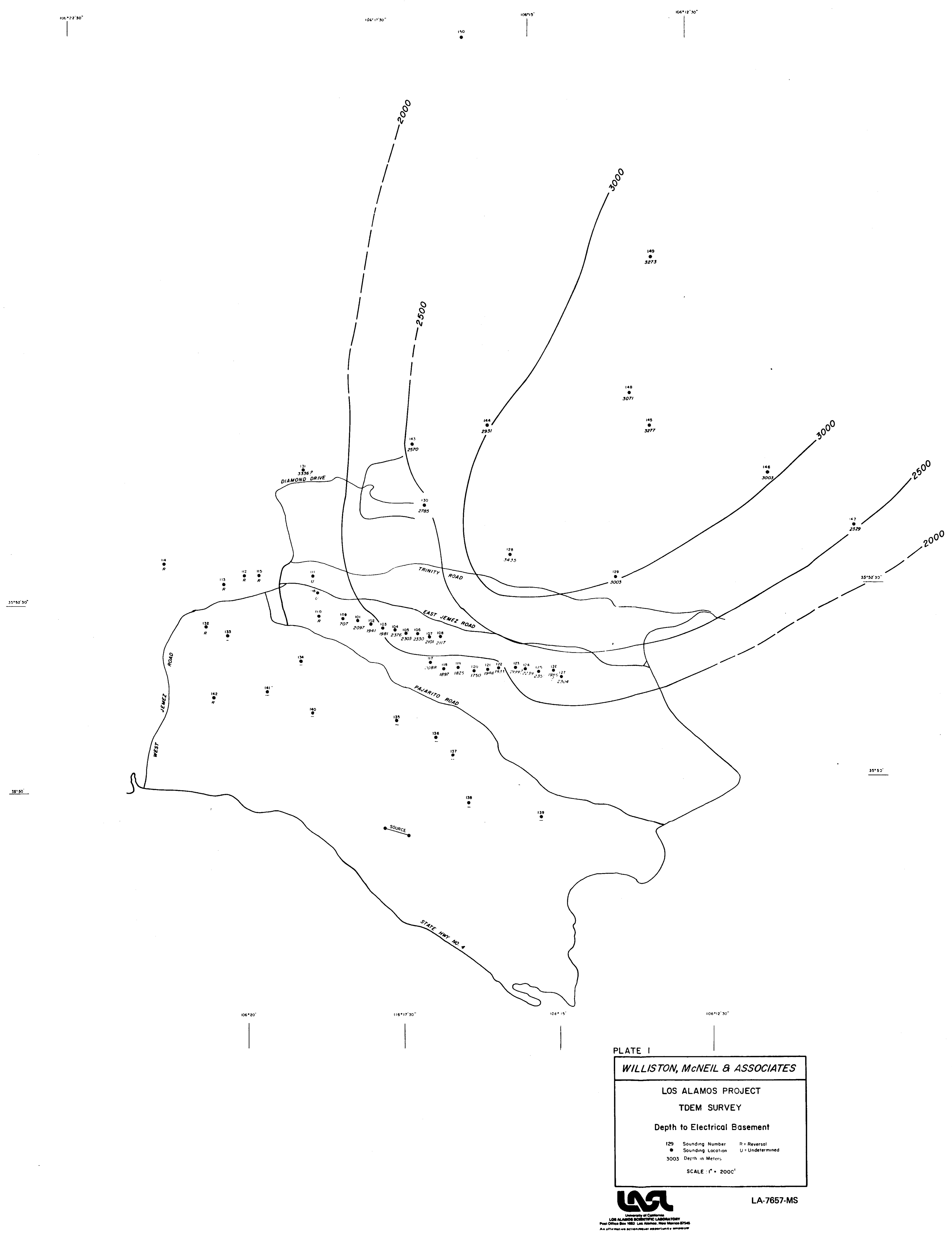


" p"

i

i

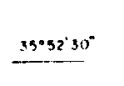

$35^{\circ} 50^{\circ}$

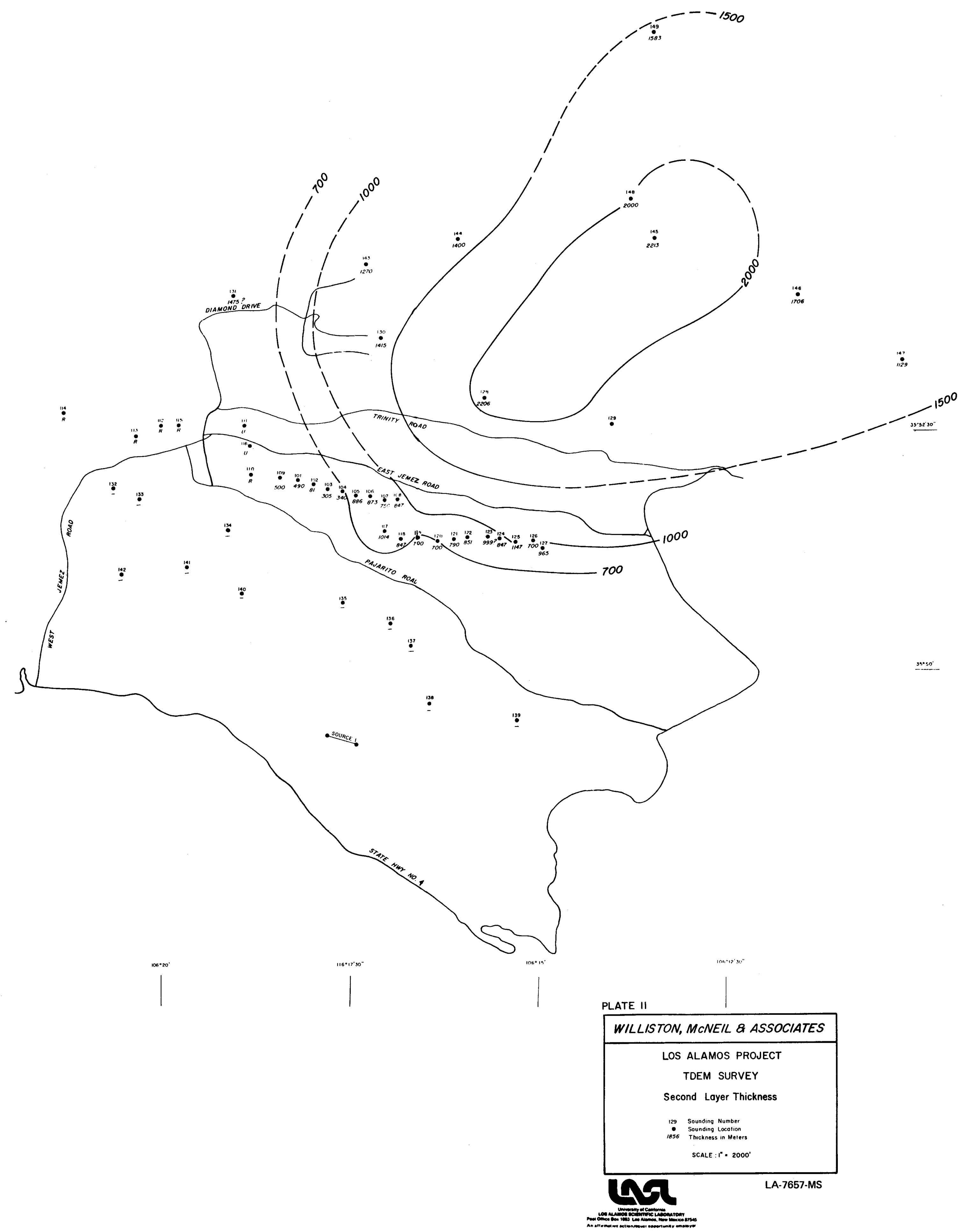


p

T

$\because$

in

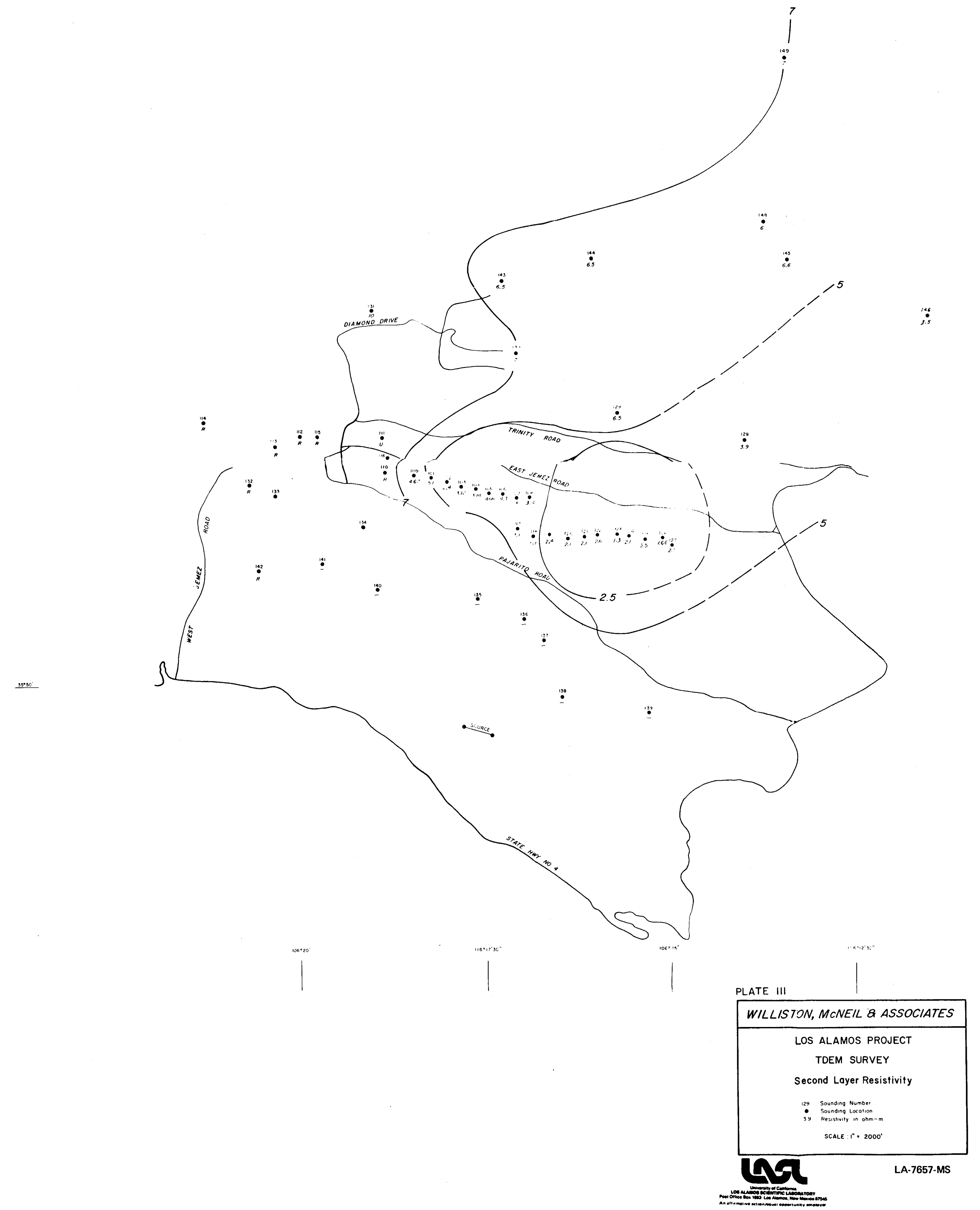

